\title{
LA MODERNIZACIÓN EDUCATIVA EN ESPAÑA EN UN ESCENARIO DE CAMBIO SOCIAL Y DE APERTURA DEMOCRÁTICA. CONVERSACIONES CON PEDRO CASELLES BELTRÁN, DIRECTOR GENERAL DE EDUCACIÓN BÁSICA (1976-1982) ${ }^{\alpha}$
}

\author{
Educational modernization in Spain in a scenario of social change \\ and democratic openness. Conversations with Pedro Caselles \\ Beltrán, General Director of General Basic Education (1976-1982)
}

\section{Xosé Manuel Malheiro Gutiérrez ${ }^{\mathrm{B}}$}

Resumen. Este texto es un extracto de varias conversaciones mantenidas con Pedro Caselles Beltrán (1937), maestro de Enseñanza Primaria, licenciado en Filosofía y Letras, especialidad Pedagogía, e inspector de educación. Pedro Caselles desempeñó las delegaciones provinciales de educación de Lugo, Cádiz y A Coruña (1970-1976); más tarde fue subdirector General de Centros no Estatales y director general de Enseñanza Básica (1977-1982). En el texto se aborda su trayectoria profesional, síntesis de gestión administrativa y acción política, con especial detalle en la etapa que ejerció como delegado provincial y posteriormente alto cargo en el Ministerio de Educación y Ciencia (MEC), bajo cuyo mandato se llevaron a cabo diversas iniciativas, entre las que destaca el impulso a la Ley General de Educación y Financiamiento de la Reforma Educativa (LGE) de 4 de agosto de 1970 mediante la renovación de los Programas de la Educación General Básica.

Palabras clave: Política educativa; Ley General de Educación; Programas Renovados de la EGB; Educación y Transición española.

\footnotetext{
${ }^{\alpha}$ Este texto es un extracto elaborado a partir de varias conversaciones mantenidas con Pedro Caselles Beltrán en A Guarda (Pontevedra) durante el verano de 2019 y en Madrid, en el mes de diciembre de ese año; de algunas notas extraídas de prensa de la época y de referencias bibliográficas que aparecen al final. Los párrafos que figuran en cursiva corresponden a las intervenciones del entrevistado en dichas conversaciones.

${ }^{\text {B } ~ U n i v e r s i d a d e ~ d a ~ C o r u n ̃ a . ~ F a c u l t a d e ~ d e ~ C i e n c i a s ~ d a ~ E d u c a c i o ́ n . ~ C a m p u s ~ d e ~ E l v i n ̃ a . ~} 15008$ - A Coruña, España. jose.malheirog@udc.gal (D) https://orcid.org/0000-0002-5992-9522
}

Cómo citar este artículo: Malheiro Gutiérrez, Xosé Manuel. «La modernización educativa en España en un escenario de cambio social y de apertura democrática. Conversaciones con Pedro Caselles Beltrán, Director General de Educación Básica (1976-1982)». Historia y Memoria de la Educación 14 (2021): 695-745 
Abstract. This text is an extract from several conversations held with Pedro Caselles Beltrán (1937), a primary school teacher with a degree in Philosophy and Humanities, specialising in Pedagogy, and an education inspector. Pedro Caselles occupied the provincial education offices in Lugo, Cádiz and A Coruña (1970-1976); later he was Deputy Director General of Non-State Schools and General Director of Basic Education (1977-1982). The text deals with his professional career, a summary of administrative management and political action, with particular emphasis on his time as a provincial delegate and later as a senior official in the Ministry of Education and Science (MEC). Under his mandate, several initiatives were carried out, including the promotion of the General Education and Financing of the Education Reform Act (LGE) of 4 August 1970 through the renewal of the Basic General Education Programmes.

Keywords: Education policy; General Education Act; Renewed programmes of the EGB; Spanish Education and Transition.

\section{La Ley General de Educación desencadenó una toma de conciencia social sobre la educación como inversión a medio y largo plazo, como factor productivo e instrumento de movilidad social}

«Pónganse a remar inmediatamente y vayan construyéndose la barca durante la travesía». Éste fue el consejo que el ministro de educación José Luis Villar Palasí (1922-2012) dio a los primeros delegados provinciales de su Ministerio, convocados a Madrid para la toma de posesión en las respectivas Delegaciones reguladas por la nueva Ley General de Educación. ${ }^{1}$ Entre aquel núcleo inicial, formado por inspectores de carrera, catedráticos de bachillerato y técnicos de la Administración civil del Estado ${ }^{2}$ encargados de implantar la reforma estaba Pedro Caselles Beltrán. Una ley que, como el mismo señaló con mirada retrospectiva años después,

\footnotetext{
1 Las Delegaciones provinciales del Ministerio de Educación se crean, aunque no se desarrollan, por un Decreto de la Presidencia del Gobierno de 27/11/67 sobre medidas generales de restricción del gasto en la Administración estatal. Se regulan y desarrollan por primera vez por Decreto de 25/09/68 y, ya tras la LGE, se las regula de nuevo por decreto de 31/12/70 dándoles la estructura que mantendrían básicamente hasta su desaparición con las transferencias autonómicas.

2 Con posterioridad, en algún momento, se nombraron incluso delegados sin relación alguna con el Ministerio, al tratarse de un puesto político, de libre designación sin requisitos académicos o docentes específicos.
} 
puso en pie sobre el territorio la modernización radical del mapa educativo español en sus proyecciones materiales, personales y funcionales, y que pese a frustraciones y demoras en su aplicación generalizada, desencadenó una toma de conciencia de la sociedad sobre la educación como inversión a medio y largo plazo, como factor productivo e instrumento de movilidad social. ${ }^{3}$

El apellido Caselles viene ligado a la inspección educativa desde la Segunda República cuando su padre, Pedro Caselles Rollán (1903-1983), se incorporó como jefe de la Inspección de Pontevedra después de aprobar la oposición en 1932. Fue sancionado, tras la rebelión militar y confinado en la prisión de la isla de San Simón (Arcade, Pontevedra) ${ }^{4}$ durante la guerra civil. Afortunadamente logró salir con vida, pero fue apartado del cargo hasta 1954, cuando el ministro Joaquín Ruíz Giménez (1951-1956) procede a la revisión de los expedientes de depuración de los educadores supervivientes, sancionados durante la guerra civil, y a su rehabilitación. Esto permitió que Pedro Caselles Rollán todavía pudiera desarrollar una extensa carrera en el ámbito de la inspección hasta su jubilación en $1973 .{ }^{5}$

Su hijo, Pedro Caselles Beltrán, nació en plena guerra civil el 8 de marzo de 1937 en Vilachán (Tomiño, Pontevedra), donde su madre, Margarita Beltrán Herrerín, ejercía como maestra. En medio de aquella tragedia, Margarita tuvo el valor de acercarse con el bebé hasta la citada cárcel para que padre e hijo pudieran conocerse. En la escuelita rural de Vilachán aprendió a leer y a escribir, y muchas cosas más. Los primeros doce años de mi vida fueron maravillosos, y por eso inolvidables. Años de juegos infantiles en una naturaleza plena de belleza, cuando el tiempo se medía por el sol; cuando no había televisión, cuando las estaciones del año regian nuestros comportamientos...

\footnotetext{
3 Pedro Caselles Beltrán, «Ley de Ordenación General del Sistema Educativo (LOGSE)», Razón y Fe. Revista Iberoamericana de Cultura 233 (1996): 262.

4 Sobre los campos de concentración y confinamiento franquistas, puede consultarse una obra reciente: Carlos Hernández de Miguel, Los campos de concentración de Franco. Sometimiento, torturas y muerte tras las alambradas (Barcelona: Ediciones B., 2019). Sobre la cárcel de San Simón puede verse el documental: Aillados [Aislados] (Antón Caeiro, 1995) que recoge el testimonio de algunos de los presos sobrevivientes en el lazareto de la isla de San Simón, considerada uno de los muchos puntos negros de la represión franquista en Galicia.

Dos colegios públicos recibieron el nombre de Pedro Caselles Rollán: uno en Calzada de Valdunciel (Salamanca), en 1981, y otro en Xove (Lugo), en 1998.
} 


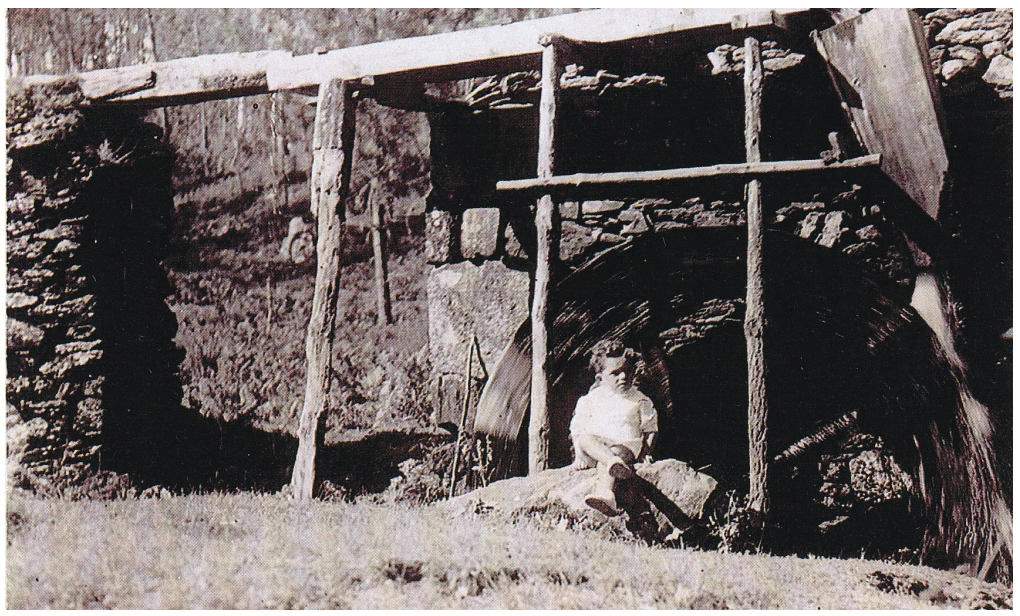

Imagen 1. Tomiño (Pontevedra), 1939. Posando frente al molino de agua de A Regueira.

Después de aprobar el examen de ingreso y superar el primer curso por libre en el Instituto Masculino de Pontevedra, cursó el Bachillerato Superior en Torrelavega (Santander) hasta que la reposición de su padre como inspector de enseñanza primaria llevó a la familia de nuevo a Galicia, y en Lugo, donde se instalan, se formó como maestro de Enseñanza Primaria en la Escuela Normal (1956); seguidamente inició la carrera de Filosofía y Letras en la Universidad de Oviedo residiendo en el Colegio Mayor Valdés Salas, institución en la que aprendí muchas cosas valiosas que no están en los libros. Su director, Luis Vega Escandón, más tarde diputado y eurodiputado, me descubrió la democracia cristiana. Alli dirigí Altavoz, la revista del colegio, sucediendo a Fernando Suárez, años después ministro, y me permitió conocer a personajes como Camilo José Cela. Recuerdo que, en una celebración, a la que habitualmente asistian diversas personalidades, escuché y retuve esta frase, pronunciada en un discurso por el Presidente de la Audiencia: "Ustedes están llamados a ser los nuevos dirigentes de nuestra sociedad».

Tras la experiencia ovetense se trasladó a Madrid para cursar la especialidad de Pedagogía en la Universidad Central (1961), donde dedicó muchas horas al trabajo apostólico, integrando el excelente equipo del Consejo Nacional de Jóvenes de Acción Católica, en la Delegación Nacional de Aspirantes. Fueron años de entrega entusiasta formándome al lado de personas que, más tarde, ocuparían responsabilidades importantes en 
la vida civil y eclesiástica, como Salvador Sánchez Terán, Mauro Rubio o José Manuel Estepa Llaurens.

Defendió su Tesis de Licenciatura en 1962 sobre la situación de las escuelas rurales de la montaña de Lugo -que me las visité a caballo siendo alumno de la Facultad - bajo la dirección de Víctor García Hoz. Recuerdo a don Víctor como una figura de la Pedagogía, pero yo he sido un estudiante de síntesis, no de memoria. Quien realmente me impregnó de contenido pedagógico fue el profesor y más tarde inspector Manuel Rivas Navarro, que nos daba unas clases impresionantes de didáctica especial, muy densas de contenido.

No hay duda de que la elección del tema vino determinada por su origen rural y la experiencia de un infante acomodado que comparte vivencias y sentimientos con otros niños de familias humildes en una Galicia de posguerra: hijos de labradores, trabajadores sufridos, cuidadores de la tierra, el monte, los ganados. Experiencias vividas, conocimientos aprendidos: rozar o toxo, ${ }^{6}$ segar os penascos, ${ }^{7}$ cavar y cortar el maíz, vendimiar, elaborar el aguardiente, participar en la matanza... ir a la feria, a las fiestas... Toda una cultura eminentemente rural con su vocabulario específico, su propia metodología, su sabiduría ancestral, que se hizo más consciente cuando, viviendo ya en la ciudad, me di cuenta de que los niños campesinos éramos poseedores de una cultura mucho más rica que los niños urbanos. Alli aprendi a hablar gallego.

Pero la escuela en que se había educado el futuro inspector estaba tocando a su fin. El sistema educativo debía ser reformado en su totalidad, superando el viejo modelo de la Ley Moyano que, con diversos retoques sectoriales, seguía dictando en España. ${ }^{8}$ Su padre, Pedro Caselles Rollán, con una amplia experiencia desde 1925 como maestro en Calzada de Valdunciel (Salamanca); con años en la inspección de la escuela rural y otras tareas educativas en la enseñanza privada cuando

\footnotetext{
6 Cortar los brotes de retamo espinoso, un arbusto característico de los montes gallegos y, en general, del norte de la Península, usado en las cuadras como cama del ganado que, al cabo de unos meses, servía también de abono en los campos.

7 Segar la hierba que se siembra durante todo el año para alimentar el ganado.

8 Puede consultarse, sobre este asunto, a Manuel de Puelles Benítez, Educación e ideología en la España contemporánea (Barcelona: Labor, 1991). Más recientemente, Modernidad, republicanismo y democracia: una historia de la educación en España (1898-2008). (Valencia: Tirant lo Blanch, 2009).
} 
fue depurado en el cargo, formaba parte de esa corriente: «O se revoluciona todo, o más vale bombardearlo». De ese modo, y gracias a una intervención arriesgada pero eficaz, siendo inspector jefe en Lugo, Caselles Rollán va a propiciar el impulso de lo que se conoció como Plan Galicia de construcciones escolares y que sería piloto para trasladar más tarde a otras zonas del Estado, cuando la reforma del 70 estaba ya en sazón. Su hijo lo recuerda con orgullo: Cansado de observar en sus visitas el estado de abandono de la escuela rural de montaña, en las $\mathrm{Na}$ vidades del año 1969, mi padre encargó a un conocido fotógrafo de Lugo un reportaje en blanco y negro, de niños y de escuelas de la sierra de $O$ Courel. Luego las montó en un álbum y felicitó al ministro Villar Palasí con ese álbum. Alli aparecían unos niños desnutridos, harapientos, desaseados... que acudían a la escuela cuando podían, en locales desvencijados. Porque su prioridad no era la instrucción sino la subsistencia. Bueno, una tragedia que demostraba que, en algunos lugares de España, poco o nada había cambiado desde que en 1933 Luis Buñuel filmara Las Hurdes. Tierra sin pan. Y el Ministro le contestó con una carta muy emocionada, en la que le confesaba haber quedado profundamente impresionado. Y que ese álbum había contribuido a tomar la decisión de declarar a Lugo provincia piloto de construcciones escolares, porque no consentía que hubiera niños viviendo en esas condiciones. Y, efectivamente, siendo yo inspector en Lugo, llegó una comisión del Banco Mundial al Ministerio, y mi padre -no sé si es que veía en mí que yo podía influir mejor en aquellos jóvenes técnicos europeos, entre los que había algún español...los recibió en su despacho, pero me encargó que los acompañara en diversas visitas, porque seguramente consideró que generacionalmente estábamos más próximos. Yo les acompañé y elegimos unos centros... y ahí empieza un plan de construcciones muy importante, en el que yo me involucro, e inspeccionamos varios solares con los arquitectos municipales, para ver su idoneidad.

Rematada la licenciatura, regresa a Lugo para preparar la oposición de ingreso al Cuerpo de Inspectores de Enseñanza Primaria a la vez que realizaba las prácticas docentes necesarias para poder presentarme. Ese mismo año fue nombrado Jefe del Programa de Educación en Alimentación y Nutrición, del Servicio Escolar de Alimentación y Nutrición en esa provincia, puesto que ocupó hasta 1965, cuando gana la oposición y pasa a desempeñar el cargo de Inspector Comarcal de Viveiro (Lugo). 
Siendo yo un joven inspector, ni siquiera de Lugo, sino comarcal de Viveiro, y estando todavía en prácticas el primer año tutorado por un inspector jefe-en realidad mi padre debería ser el tutor, pero a mí me tutoró el secretario provincial de la Inspección de Lugo, Ruiz Tablado, que había sido n. ${ }^{\circ} 1$ de su oposición, y procedía del Instituto Escuela-, recuerdo que nos visitó Joaquin Tena Artigas, Director General de Enseñanza Primaria, al que después me referiré. Recuerdo que me preguntó cuántos días estaba yo en Viveiro, cabecera de comarca. "Pues estoy lunes, martes, miércoles y me vengo el jueves para Lugo». "Y el resto de la semana?" preguntó... Yo le respondí: «Señor Director General, con el debido respeto, yo no me puedo quedar alli toda la semana. Primero, porque soy un inspector tutorado, y debo estar, y tener un contacto, con el Consejo de Inspección y con mi tutor. $Y$, además, porque si yo me quedo el fin de semana allí, el único sitio a donde puedo ir es al Casino, y en el Casino están los caciques de Vivero. En algún caso están casados con esposas, que son maestras, y que no están al frente de la escuela, sino que tienen sustitutas mal pagadas... ». Eran vicios normalizados que debían erradicarse en pos de una cultura escolar más moderna y responsable. A esas maestras les daba un plazo para cesar o reintegrarse, y asi acabar con dichas ilegalidades.

Sobre este asunto, es interesante recuperar las siguientes palabras de la inspectora M. ${ }^{\mathrm{a}}$ Teresa López del Castillo:

Creo que no exagero al afirmar que la escuela pública (nacional se llamaba entonces) estaba profundamente desprestigiada y no sin motivo. Por un lado, las bajísimas retribuciones del profesorado no podían atraer o retener a los más capaces que preferían abrir una «academia» o dedicarse a otros trabajos mejor remunerados. O bien, y este era el caso más frecuente en el medio rural, practicaba sistemáticamente el absentismo buscando un sustituto, generalmente sin título y si formación, que quedaba al frente de la escuela. A lo largo de los años cincuenta la actuación de la inspección fue un factor decisivo para acabar con este absentismo que obligó a incoar cientos de expedientes disciplinarios. ${ }^{9}$

\footnotetext{
9 M. ${ }^{\text {a }}$ Teresa López del Castillo, «La inspección que he vivido», en Fundamentos de supervisión educativa, coord. Eduardo Soler Fierres (Madrid: La Muralla, 1993), 256.
} 


\section{Mis primeros años fueron apasionantes. Me enamoré de mi profesión como inspector, visitando las escuelas rurales, unas veces en moto, otras en un Seat 600. En zonas como la sierra de $\mathbf{O}$ Courel hacía las visitas a caballo, o incluso a pie}

A partir de ese momento y hasta su jubilación, Pedro Caselles Beltrán va a desarrollar una intensa actividad profesional como inspector de la Administración del Estado en diferentes instituciones y cometidos dependientes del Ministerio de Educación. Una densa trayectoria en la que concilia gestión administrativa y actuación política. Entre el año 1965 y 1970 ejerció como inspector de enseñanza primaria en la provincia de Lugo ostentando el cargo de Vicesecretario del Consejo de Inspección e Inspector Ponente de Colonias Escolares y Escuelas Hogar. Empecé como inspector después de una oposición muy numerosa que duró nueve meses. Hacía años que no había oposiciones. Parte de los inspectores en activo habian sido nombrados a dedo. Eran maestros y gente de confianza del Régimen que ocupaban vacantes causadas por depuraciones, sobre todo, de la guerra civil; entre ellos, gente exiliada en América... Fueron unos años apasionantes en los que me enamoré de mi profesión, visitando las escuelas rurales, unas veces en moto, otras en un Seat 600... En zonas como la sierra de O Courel hacía las visitas a caballo, o incluso a pie. En ocasiones me prestaban un caballo que me permitía llegar a las aldeas más apartadas. Por la rutina a la que le sometía su dueño, y mi falta de pericia, aquel animal sabía detenerse a la puerta de cada taberna, lo que dificultaba con cierto retraso mi trayecto. $Y$ así se lo comenté, en tono jocoso, a su propietario: "Don Fulano, tenemos un problema con este caballo, que se para en todas las tabernas...", a lo que me contestó, socarrón: "Pues ahora tenemos dos, don Pedro, iporque se va a parar también en todas las escuelas!!» [risas]. La precariedad de aquellas aulas, el aislamiento intelectual de los profesores, la pobreza y necesidad de muchas aldeas solitarias fueron labrando en mi una concepción humanitaria de la profesión. Visitaba en mayo o junio, con la nieve ya fundida y el primer sol calentando. En este tiempo, los maestros hacian leer o cantar en alto a los rapaces, tal como escribió Machado: "Y todo un coro infantil, van aprendiendo la lección, mil veces ciento, cien mil; mil veces mil, un millón...». 


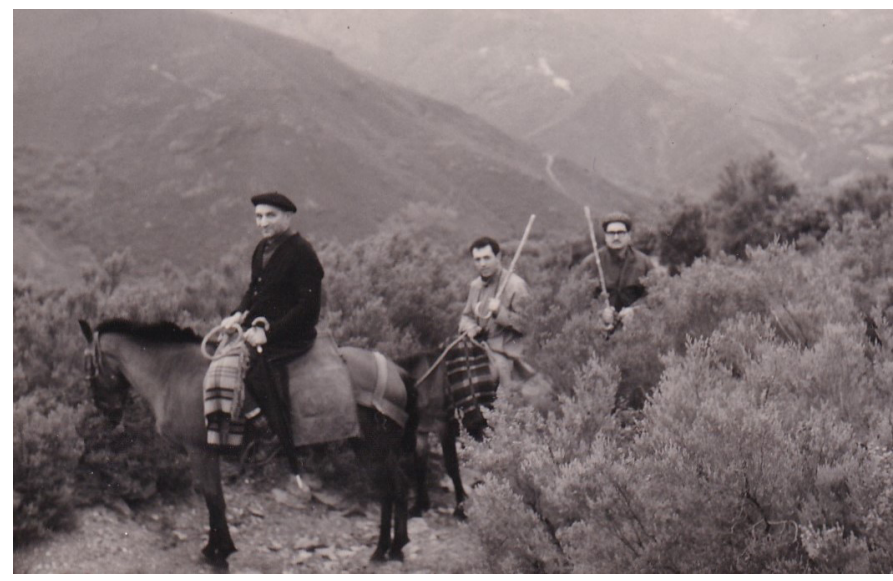

Imagen 2. Seoane do Courel (Lugo), 1966. Visita de inspección a la escuela de la parroquia de Seoane, acompañado por el maestro Raposo y un alumno de Magisterio.

En 1970 fue nombrado primer Delegado Provincial del Ministerio de Educación y Ciencia en Lugo: Fue un acontecimiento inesperado que condicionaría durante muchos años mi trayectoria profesional y existencial. Con la creación de las delegaciones provinciales, se descentraliza el poder simbólico y meramente académico de los rectores, que gobernaban a distancia. Entonces, de repente, a los institutos en cada provincia se les pone un jefe, que respondía, según el caso, a una variada tipología: inspectores autoritarios, paternalistas, distantes, empáticos; cultos o menos cultos. Inspectores evasivos, o bien, cargados de profesionalidad y sentido de compromiso con la Administración y las comunidades educativas... Porque la función inspectora, poco aceptada en abstracto, se singulariza, perfila y humaniza a través de una variada tipología, y esto tuvo al principio algunas reacciones y reticencias... Fueron años de entrega y trabajo, de esfuerzo y resistencias que vencer, que dieron como resultado la construcción de muchos colegios en cabeceras de comarca y núcleos en expansión, así como institutos de bachillerato y centros de formación profesional, además de creación de bibliotecas y restauración de monumentos. En este tiempo conseguimos emprender la rehabilitación de la Muralla Romana de Lugo, que propició entonces, por su monumentalidad e historia, el inicio del proceso que llevó a la declaración de Patrimonio de la Humanidad por la UNESCO en el año 2000, gracias al Subdirector General de Bellas Artes Ramón Falcón. 


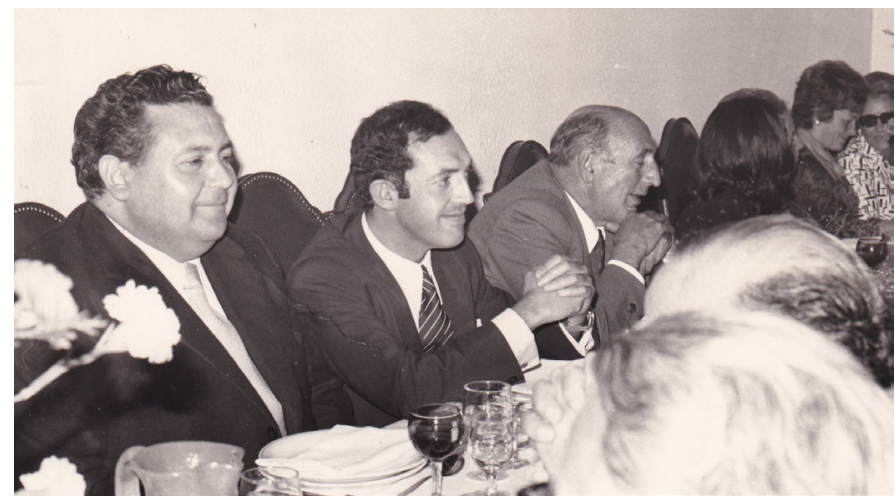

Imagen 3. Lugo, 1972. José Paz Ares, Pedro Caselles Beltrán y Pedro Caselles Rollán.

Su implicación en la puesta en valor del milenario monumento le reportó el reconocimiento municipal al ser nombrado Hijo adoptivo de la ciudad de Lugo en 1973. Anteriormente, en diciembre de 1972, el Ministerio de Educación y Ciencia se disponía concederle el ingreso en la Orden Civil de Alfonso X El Sabio, con la categoría de Encomienda. ${ }^{10}$

Como consecuencia de la puesta en marcha de los planes de construcciones escolares derivados de la aplicación de la LGE, el Ministerio de Educación se convierte en un motor importante del sector de la construcción y en la primera empresa contratante de transporte y alimentación del país. Tanto es así, que en algún momento tuvimos que advertir: "Ya es hora de dejar la política de ladrillos por la de personas...». Lo que sucedió -aclara Pedro Caselles-, es que cuando la Ley se aprueba, en algunas provincias, en concreto en Galicia, estamos trabajando ya sobre la partitura... no digo pedagógica de la Ley, sino la partitura ladrillesca por la propia configuración demográfica y geográfica del contexto... Yo recuerdo que años después, un día dije en una reunión de delegados provinciales en Madrid: "Creo que tenemos que empezar las reuniones de pedagogía y de educación a la vez. que el ladrillo». No se podía descartar el ladrillo, por el plan de construcciones escolares, pero habia una obsesión ladrillesca. Luego me enteré que los técnicos, que en algún caso habian sido delegados administrativos de enseñanza primaria, se habian reservado unas prebendas económicas

10 Pedro Caselles fue objeto de numerosos reconocimientos y condecoraciones a lo largo de su carrera. Muchos de ellos no aparecen en este texto, pero están reflejados en su totalidad en el siguiente perfil biográfico digital: http://galegos.galiciadigital.com/es/pedro-caselles-beltran. 
de algún porcentaje en las construcciones, o algo así [risas]. Y no sé si alguno de nosotros lo denunció al Ministerio... Otra de las cuestiones relacionadas con el ladrillo era la falta de planificación urbanistica en algunas zonas, sobre todo cordones industriales que nacían con el desarrollismo, en los que no se preocupaban de garantizar terrenos para servicios docentes. Esto nos ponía frente a grandes aglomeraciones urbanas que carecían de puestos escolares próximos y a las que había que atender después con transporte y otros servicios que acaban encareciendo el sistema.

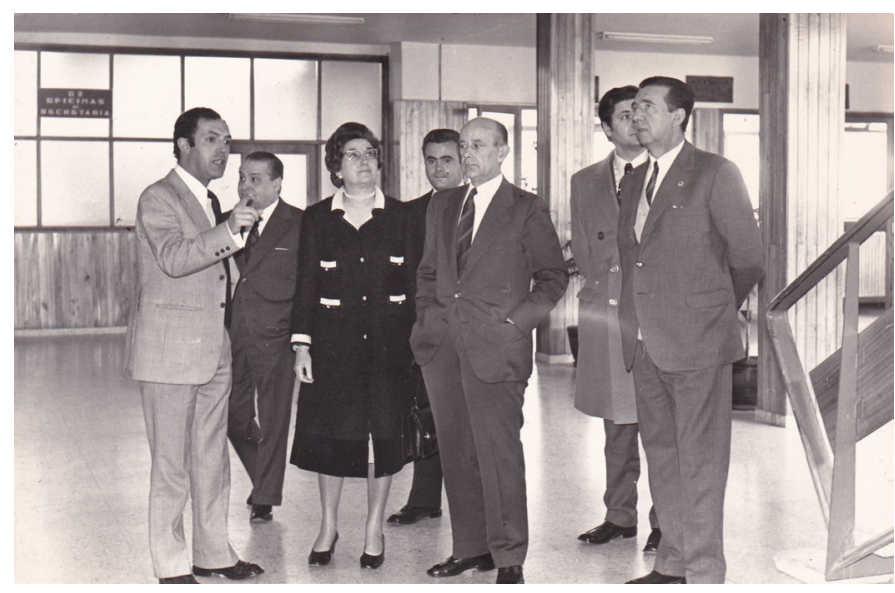

Imagen 4. Lugo, 1972. Visita de la Directora General Ángeles Galino, y autoridades lucenses.

Sobre este aspecto, coincide Antonio Viñao, quien en 1980 escribía en la Revista de Educación:

La época (década de los 70) de mayor esfuerzo estatal (insuficiente, pero el mayor) de nuestra historia educativa en materia de construcciones docentes, se ha realizado sobre la base de un desastroso planeamiento urbanístico, con todo lo que ello comporta desde el punto de vista económico (mayores gastos de construcción por tratarse de terrenos residuales donde la edificación sólo era posible con un coste superior), social (largos desplazamientos y movimientos de la población escolar) y educativo (tanto en cuanto a la planificación y distribución del alumnado en las grandes ciudades, como en cuanto a la organización interna de los centros, manejabilidad de los mismos e integración en el entorno 
urbano). Con el Reglamento de $1978^{11}$ algo se mejora en relación a la situación precedente, pero, como hemos visto, todavía subsisten lagunas, incoherencias y contradicciones, y, lo que es más importante, una inercia entre los profesionales que realizan planes urbanísticos y los organismos responsables de su aprobación, que da por válidos planes que no resisten un análisis a fondo del tema, en especial, cuando cualquier objeción o exigencia de elevación de la reserva de suelo para fines docentes se ataca con la consabida referencia a que si no se aprueba tal o cual plan se está fomentando el paro (y ello se oye tanto desde la derecha como desde el centro o la izquierda). ${ }^{12}$

Efectivamente, como puntualiza Caselles, No se trataba de poner a disposición un trozo de terreno, encima de un basurero en un lugar apartado sin interés urbanístico, no, pues había que medirlo, ver si habia carretera para el transporte escolar, en fin, todos los requisitos técnicos y demográficos. En algunos casos había que recurrir al chantaje cuando algún alcalde se resistía: "No se preocupe, que tengo una lista de peticionarios, pasa al siguiente...», y generalmente solía funcionar.

\section{Cuando algunos críticos me dicen que se suprimieron escuelitas en entornos rurales... hay que pensar cómo funcionaban en zonas más apartadas, con todos sus estigmas... sin control y en completo aislamiento de alumnos y maestros}

Con la LGE se generalizó la agrupación escolar en colegios de diversas unidades, algunos mixtos, pero también separados por sexos... En los colegios de ocho unidades ya, sí. Se asume y no pasa nada, porque los pros son mayores que los contras. Es decir, cuando a veces algunos críticos me dicen que se suprimieron muchas escuelitas en entornos rurales... hay que pensar cómo funcionaban esas escuelitas en las zonas más apartadas, con todos sus estigmas... sin control y en completo aislamiento de alumnos y maestros. Que esa gente pasara a un colegio de ocho unidades

\footnotetext{
11 Se refiere al Reglamento de Planeamiento, aprobado por D. 2.159/1978, de 23 de junio correspondiente a la Ley sobre Régimen del Suelo y Ordenación Urbana (Texto Refundido aprobado por R. D. 1346/1976, de 9 de abril).

12 Antonio Viñao Frago, «El planeamiento urbanístico-docente: un análisis de sus necesidades y problemas», Revista de Educación 264 (1980): 75-76.
} 
significó un estímulo para cuestiones tan básicas como el aseo personal, el vestido, desplazarse en autobús o la garantía de alimentación escolar sana y equilibrada. Además, para compañeros de pupitre que ancestralmente entre aldeas habian sido casi enemigos, o adversarios, que acababan peleándose en las romerías, la agrupación significó en aquel momento, sociológicamente, un avance. Fue más allá de separar por sexos -o segregar, como se diría hoy-al alumnado que, por otro lado, seguía compartiendo otros espacios socioculturales de convivencia comunal en la mayor parte del territorio rural de aquella España de los años setenta. A mi juicio, la concentración supuso una mejora en la calidad de la enseñanza. Además, habia imperativos de carácter económico que hacían imposible mantener las escuelas rurales. De todos modos, el Ministerio no siguió una política de macro-concentraciones, especialmente en un contexto como el de Galicia. La concentración escolar acabó siendo la nueva escuela rural que aquellos tiempos demandaban, y la escuela unitaria y mixta se mantuvo en donde las condiciones geográficas, demográficas o meteorológicas lo exigieron. En muchos casos, y para resolver la escolarización de los niños procedentes de casas ultradiseminadas y muy bajo censo se crearon en algunas cabeceras de comarca las denominadas Escuelas Hogar o internados. Cuando el tiempo lo permitía, y en vacaciones, los niños volvían a la convivencia familiar de sus hogares. ${ }^{13}$

Otra novedad importante fue la capacidad de organización y la autonomía que, al menos en teoría, la nueva Ley otorgaba a los centros educativos... Realmente fue un gran avance. En alguna ocasión, yo propuse cambiar los horarios escolares, pasando a negociarse con los maestros, en muchos casos de modo alegal, tanto en zonas de interior como de costa. Porque, por ejemplo, durante la marea baja, que es la hora del marisqueo, era importante que los niños ayudasen a sus padres. Esto ocurrió en $O$ Vicedo, en la costa de Lugo. Era muy importante que la escuela se adaptase al medio y el medio a la escuela, evidentemente, en todos los entornos del Estado. Y los niños iban a la escuela y marisqueaban. Las dos cosas. Como decía Ortega en 1930: "Cuando una nación es grande, es buena también su escuela. No hay nación grande si su escuela no es buena. La escuela, como institución normal de un país, depende mucho del aire

13 La historiografía educativa actual escrita desde Galicia suscita algunas discrepancias con esta valoración que, sin embargo, introduce puntos de vista que es oportuno tomar en consideración para un más adecuado análisis. 
pedagógico producido dentro de sus muros, pero también del aire público en que integramente flota». Yo creo que solo cuando hay ecuación entre la presión de uno y otro aire, la escuela es buena.

En los últimos años del franquismo se observa la emergencia de una considerable inquietud reivindicativa sobre el uso de las lenguas denominadas vernáculas -gallego, euskera y catalán- en el ámbito educativo. Sobre este asunto, cuando yo llegué a la Dirección General, la LGE había iniciado el camino de cierto reconocimiento oficial a través del Decreto regulador de las lenguas regionales españolas -1433/1975 de 30 de mayo-, que autorizaba, de modo experimental, el estudio de las lenguas llamadas nativas como materia voluntaria en los centros de Educación Preescolar y de Educación General Básica, aunque fundamentando argumentos proteccionistas y culturalistas muy básicos. A partir de ahí se abrió un camino que contó con un estímulo importante al ordenar, desde la Dirección General, la publicación de tres monografías sobre las lenguas catalana, vasca y gallega. Poco después llegaría el Estado de las Autonomías, con políticas lingüísticas determinadas en cada territorio, y cada una siguió su camino. Sobre este aspecto, es interesante el apunte que ofrece el profesor Antón Costa en esa etapa:

De muy poco servía la contemplación en el artículo 17 de la LGE de 1970 de la posibilidad de «cultivo, en su caso, de la lengua nativa», ni tampoco el decreto de 1975 sobre «lenguas regionales» (BOE de 15 de noviembre de 1975), aunque fuesen espitas de permisividad para una pequeña presencia del gallego en las aulas. Porque, la misma modernización y la creación de concentraciones escolares estaban operando como factores de desgalleguización y de castellanización en unas circunstancias ya bien azarosas. «En Galicia, la discriminación escolar pasa necesariamente y en primer lugar por la lengua», afirmaba el sociólogo Pérez Vilariño en 1979, al tiempo de apreciar una fuerte asociación entre el nivel de vida familiar alto y escolares de lengua castellana, por un lado, y nivel bajo y lengua gallega, por el otro, con correlatos similares a la hora de hablar del rendimiento académico. ${ }^{14}$

14 Antón Costa Rico y Manuel Bragado, «El libro escolar en gallego», en Historia ilustrada del libro escolar en España, Volumen II: «De la posguerra a la reforma educativa», dir. Agustín Escolano Benito (Madrid: Fundación Sánchez Ruipérez, 1998), 499-500. 
Sobre los motivos, externos e internos, que influyeron en la gestación de la LGE, señalan Gabriela Ossenbach y Martínez Boom, ${ }^{15}$ con quienes también coincide Agustín Escolano, que en la década de 1960, algunos países del área mediterránea -España, Portugal, Italia, Yugoslavia, Grecia y Turquía- fueron considerados «en desarrollo» y agrupados en el Proyecto Regional Mediterráneo dentro del contexto europeo y, por tanto, destinatarios y receptores de estrategias de cooperación que partían de la acción de diversos organismos como la Organización para la Cooperación y el Desarrollo Económicos (OCDE), el Fondo Monetario Internacional (FMI) o el Banco Mundial (BM). Algunos personajes centrales, en calidad de expertos internacionales, circularon proponiendo «recetas» muy similares para conducir los procesos de modernización en esos países. En España, estos organismos y sus asesores fueron determinantes en la gestación de la LGE bajo el discurso del desarrollo y del planeamiento cuando todavía subsistía la dictadura franquista. Hablamos de Ricardo Díez Hochleitner, que entonces ostentaba el cargo de Jefe de la División de Planeamiento de la UNESCO, posteriormente dirigió la División de Educación en el Banco Mundial en Washington; de José Blat Gimeno, Secretario del Primer Proyecto Principal de la UNESCO para América Latina; o de Joaquín Tena Artigas, antiguo funcionario en la División de Estadística de la UNESCO y director del equipo español del Proyecto Regional Mediterráneo. Tres protagonistas que, a juicio de Antonio Viñao, merecen especial atención:

Joaquín Tena Artigas, en el papel de quien no solo desbroza el camino, sino que da entrada a otros y colabora en su parte final; José Blat Gimeno, como colaborador y protagonista en un segundo plano, pero con cierta influencia, en la elaboración del Libro Blanco que precedió, en 1969, a la LGE; y Ricardo Díez Hochleitner, que fue quien convenció al ministro de la necesidad de elaborar una nueva ley que abarcara todos los aspectos, niveles y modalidades del sistema educativo. ${ }^{16}$ Los tres se moverían, en mayor

15 Gabriela Ossenbach Sauter y Alberto Martínez Boom, «Itineraries of the discourses on development and education in Spain and Latin America (circa 1950-1970)», Paedagogica Historica. International Journal of the History of Education 47 (2011): 679-700.

16 «No es aventurado pensar que la idea [de emprender una reforma global del sistema educativo] fue suya» (Joaquín Tena Artigas, «Testimonios actores de la Ley Contestación al cuestionario de la Revista de Educación sobre la Ley General de Educación veinte años después», Revista de Educación n. ${ }^{\circ}$ ext. «La Ley General de Educación veinte años después» (1992), 298). Esto lo afirma tras decir que había conocido a Díez Hochleitner en «la UNESCO en París cuando se presentó en mi despacho 
o menor medida, en ese mundo de los organismos internacionales -UNESCO, OCDE, Banco Mundial, Organización de Estados Americanos (OEA) - y el asesoramiento a distintos gobiernos en su calidad de expertos en la planificación o planeamiento de la educación y las reformas educativas. ${ }^{17}$

\section{Sobre este aspecto, Agustín Escolano añade que}

la modernización de los aparatos administrativos del sistema se acelera a partir de la incorporación de Rubio García-Mina al Ministerio, en 1956. En esta fecha se hace cargo de la Dirección General de Enseñanza Primaria J. Tena Artigas, técnico experto en estadística, bajo cuya orientación se elaborará el primer mapa escolar del país, que comportó al mismo tiempo un programa de construcciones y un plan de inversiones. Aunque estos proyectos no pudieron ejecutarse totalmente, como consecuencia de los efectos inducidos por las medidas estabilizadoras para controlar la inflación y otras circunstancias, su diseño evidenció la actitud tecnificadora de la administración educativa en esta coyuntura de transición. Conviene advertir que la entrada de nuestro país en las organizaciones internacionales exigía una adaptación formal a la «aritmética política» al uso. En este sentido, la influencia externa debe ser ponderada -más tal vez que la propia dinámica del sistema- como condicionamiento determinante en el desencadenamiento de estos procesos de modernización. ${ }^{18}$

Con motivo del vigésimo aniversario de la Ley, Joaquín Tena Artigas recordaba en la Revista de Educación:

se habían hecho planes globales de desarrollo y, sobre todo, desde el punto de vista práctico, se había conseguido que en el informe

\footnotetext{
con una carta de Ruiz Giménez, ministro de Educación Nacional», y cuando colaboró, «en representación de la UNESCO» en el curso sobre «Planeamiento Integral de la Educación» que él había dirigido en Madrid en 1962. Cita tomada de Antonio Viñao, «La Ley General de Educación de 1970: ¿final de una etapa? ¿comienzo de otra?», en Modernización educativa y socialización política. Contenidos curriculares y manuales escolares en España durante el tardofranquismo y la Transición democrática, ed. Manuel Ferraz Lorenzo (Madrid: Universidad de La Laguna y Editorial Morata 2020), 131.

17 Viñao, «La Ley General de Educación de 1970: ¿final de una etapa? ¿comienzo de otra?», 131. Merece la pena consultar este trabajo para, entre otros aspectos, aproximarse a estas tres figuras.

18 Agustín Escolano Benito, «Los comienzos de la modernización pedagógica en el franquismo (1951-1964)», Revista Española de Pedagogía 50, n. ${ }^{\circ} 192$ (1992): 302.
} 
del Banco Mundial -base de nuestros Planes de Desarrollo posteriores- que dirigió Sir Hugh Ellis Rees, se incluyera la educación. En aquel momento, 1968, tanto la estructura económica como la social y cultural estaban siguiendo un proceso de acercamiento progresivo a nuestro entorno europeo y esto era ya doctrina oficial desde que en 1962 se había solicitado nuestra integración en la Comunidad Económica Europea. Además, la adaptación del campo educativo a las rápidas y profundas transformaciones que en breve tiempo se habían producido en todo el mundo y lógicamente en España, hacían el «aggiornamento» inevitable y deseable. ${ }^{19}$

En este sentido, es interesante también recuperar las palabras de Díez Hochleitner en la misma publicación, donde señala que, además de «una extendida conciencia de crisis educativa», común a diversos países del área -excesivas esperanzas depositadas por la sociedad en la enseñanza; inadecuado contenido de los planes de educación y una formación profesional poco relevante y obsoleta; fuerte presión social ante respuestas educativas insatisfactorias- influyen en España problemas específicos como la agitación estudiantil universitaria a finales de los años sesenta, bajo la influencia de Berkeley y la Sorbona. La Universidad acoge al activismo político que cobra importancia ante el agotamiento del régimen que empieza a entreverse tanto más que el plan de estabilización económica. Además, un cierto desarrollo industrial, junto con un mayor bienestar material, promueve reivindicaciones laborales y una esperanza renovada de progreso social y de libertad en democracia, unido a

la senectud del omnipotente Jefe del Estado obliga a plantear su futura sucesión y, pese al inmovilismo de algunos miembros del Gobierno, se van imponiendo cambios de diverso alcance e importancia que, poco a poco, configuran lo que en la perspectiva actual merecería ser llamada la pretransición, la cual tiene su nítido arranque con la proclamación, en 1969, de Don Juan Carlos de Borbón como Príncipe de España, sucesor a la Jefatura del Estado. ${ }^{20}$

\footnotetext{
19 Joaquín Tena Artigas, «Testimonios actores de la Ley. Contestación al cuestionario de la Revista de Educación sobre la Ley General de Educación veinte años después», 297-306.

20 Ricardo Díez Hochleitner, «Testimonios actores de la Ley. La reforma educativa de la LGE de 1970. Datos para una crónica», Revista de Educación n. ${ }^{\circ}$ ext. "La Ley General de Educación veinte años después» (1992): 266.
} 
En una línea coincidente se expresa Blat Gimeno:

En el plano político se vislumbraba el final de un régimen autoritario y anacrónico frente al cual se manifestaba, con intensidad y amplitud crecientes, la oposición de un pueblo deseoso de mayores libertades, de lograr una participación efectiva en las decisiones de orden político, social y cultural en el marco de un sistema democrático. La Administración educativa aparecía desbordada, incapaz de hacer frente a los movimientos estudiantiles iniciados desde los años cincuenta, a las exigencias de más y mejor educación por parte de la sociedad española, o de atender reivindicaciones antiguas, no satisfechas, del profesorado de los distintos niveles educativos. Se había entrado en una fase de desaliento, de impotencia y de inercia, particularmente en la última fase del mandato ministerial de Lora Tamayo. ${ }^{21}$

Como también recuerda Pedro Caselles, en efecto, historiadores y politólogos coinciden en que en 1959 termina el primer franquismo y comienza otro período en el que se combinan aspectos técnicos y económicos con elementos políticos. Fueron años de inminente transición política y social, y de una enorme responsabilidad en lo personal. Aunque Villar Palasí estaba al frente, quien dirigía la nave era su equipo. Fundamentalmente Ricardo Diez. Hochleitner, -recientemente fallecido-y José Blat Gimeno. Hochleitner era una persona poseida de una gran autoridad. Venía de ejercer otros cargos en la UNESCO, la Organización de Estados Americanos y el Banco Mundial, más tarde presidente del Club de Roma y tenía además una amplia agenda de contactos internacionales. Blat Gimeno era un ilustre inspector de brillante currículo nacional e internacional; posteriormente nombrado Vicesecretario General Técnico del Ministerio de Educación y más tarde Director General de Enseñanza; o Joaquín Tena Artigas, que había desempeñado durante doce años el cargo de Director General de Enseñanza Primaria, colaborando también con el ministro Manuel Lora-Tamayo y, más tarde, ya como Director General, con Villar Palasí, en la elaboración del Libro Blanco. Tecnócratas con una trayectoria brillante que acometieron la sustitución del falangismo por la tecnocracia del Opus

\footnotetext{
21 José Blat Gimeno, «Testimonios actores de la Ley. Apuntes sobre la elaboración y aplicación de la reforma educativa de 1968-1970», Revista de Educación n. ${ }^{\circ}$ ext. "La Ley General de Educación veinte años después» (1992): 290.
} 
de Laureano López Rodó. Una reforma encabezada por Carrero Blanco desde más arriba, que preconizaba un código de nuevos valores como la eficiencia, la productividad, la libre empresa, el crecimiento económico y el traslado al área pública de las técnicas de la empresa privada.

No debemos olvidar que, esta Ley, de la que yo soy un profundo admirador, viene condicionada, además, por una situación política que gravita en dos centros de poder muy fuertes. Por un lado, estaba la Iglesia, y por otro los principios falangistas del Movimiento, además de los militares y los monárquicos. Y esa influencia no se podía borrar de un plumazo. Por ejemplo: incluso en años posteriores, cuando a un funcionario se le daba una jefatura de sección, tenía que jurar, de rodillas, y ante la Biblia dichos principios. Era el protocolo del momento. Hubo que respetarlos y mantener un equilibrio constante con la Iglesia en sus demandas, pues fue un cambio radical. El cambio más radical que habia habido desde la Ley Moyano. Más que la Ley [de Educación Primaria] del 45. Y tanto Díez Hochleitner como Blat Gimeno jugaron un papel muy importante en este equilibrio entre la España que irreversiblemente se extinguía y la que empezaba a emerger. $Y$ siguieron la estrategia de adoptar los discursos desarrollistas que se estaban promoviendo en los foros internacionales de la época, aparentemente neutros y basados en criterios o indicadores racionales y no políticos, para introducir con habilidad elementos de modernización en el sistema educativo de un régimen dictatorial, que seguía sustentado en los pilares que acabo de señalar, y que además llevaba más de un siglo sin renovarse en sus estructuras. Hochleitner creó el Centro Nacional de Proceso de Datos, y alli se instaló un gran ordenador que habia traído de los Estados Unidos, y que fue noticia en todos los diarios de tirada nacional. Esto significó una transformación tremenda, pues entre otras cosas, pudieron conectar el Ministerio con los bancos y se empezó a abonar las nóminas de los maestros, puntualmente, mediante transferencia. Y ese aspecto vino a dignificar el salario del propio magisterio, sometido al abuso, en numerosas ocasiones, de los llamados habilitados. ${ }^{22}$

\footnotetext{
22 Habitualmente eran maestros o personas afectas al Régimen que, en lugares aislados desprovistos de oficinas bancarias, recibían de la Administración el dinero correspondiente a la paga del profesorado de su zona respectiva, al que convocaban periódicamente en su domicilio, o lugar determinado, para efectuar el reparto. Los habilitados cumplían una función importante al ser depositarios en efectivo de los salarios a repartir, pero en muchos casos también sometían a los maestros a
} 
Sobre este clima de equilibrios inestables entre un tiempo que se va y otro que no acaba de llegar, recuerda la anécdota en la toma de posesión del Gobernador Civil de la provincia de Lugo, siendo él Delegado provincial: Cuando terminó el acto, que presidía Antonio Pedrosa Latas, consejero nacional del Movimiento, indicó: "vamos a terminar a nuestro estilo". Y mientras entonaban el Cara al Sol con el brazo en alto, yo me quedé de pie y firme, respetuosamente; y conmigo algunas personas más. Desde ese día la persecución fue constante... Ese Gobernador, que tenía hijos en edad juvenil, llegó a lamentarse a Eugenio López y López, Director General: "Se nos va todo de las manos, porque estamos nombrando gente como éste - señalándome - que no es de los nuestros». A lo que yo me vi en la necesidad de responder: "Por qué dices eso, si yo informo de todo...». Sí, me contestó, "pero si yo te mando a rezar por la noche debajo de la Cruz de los Caídos, en la plaza de Santo Domingo... Tuñas Bouzón - que era un falangista local - va, y tú no vas». Yo le respondí: "Y tus hijos tampoco». Y esa era la realidad de aquel momento: una nueva generación, a la que yo pertenecía, trataba de abrirse camino... En ese sentido, yo respetaba los códigos oficiales, pero no estaba en mi actitud la voluntariedad. Yo he cantado el Cara al Sol en varias ocasiones: para aprobar la Educación política, en Bachillerato, en un campamento de verano en Laredo. Y luego, al estudiar Magisterio, habia que ser instructor elemental del Frente de Juventudes, obligatoriamente, para lo cual nos llevaban a Covaleda, en Soria. ${ }^{23}$ Y ahi estaba la clave de lo que ya se anunciaba: no hay que olvidar que aquel gobernador civil ya estaba en la fragata Baleares en plena Guerra Civil mientras yo acababa de nacer.. Y esto, en general, también se puede trasladar a la Ley General de Educación.

Pedro Caselles desarrolló su trabajo en la Delegación de Lugo hasta 1973, cuando asume el cargo de Delegado Provincial del MEC en Cádiz, invitado por el subsecretario Rafael de Mendizábal. Me habló de la dificultad y la importancia de aquella provincia, de la dimensión de sus ciudades, de sus atrasos históricos en escolarización. Y añadió que "debería

\footnotetext{
situaciones arbitrarias o de abuso en relación al abono, retrasando o fraccionando el pago, haciéndose frecuente la siguiente expresión en el momento del cobro: «De momento, váyase arreglando...».

23 El campamento de El Raso de la Nava, en Covaleda (Soria) se creó a principios de los años sesenta para llevar a cabo actividades juveniles de adoctrinamiento político según los principios del Movimiento Nacional a cargo de la Organización Juvenil Española (OJE), dependiente de la Delegación Nacional del Frente de Juventudes.
} 
probar mis alas para comprobar si era capaz de volar más alto». ¡Y me daba ocho horas para pensarlo!. En esta provincia andaluza, el nuevo Delegado se implica en una intensa labor dedicada a la creación de colegios para modernizar la red escolar pública y a la implantación de la LGE en toda su amplitud, que iría acompañada del desarrollo de una serie de principios de justicia social. Porque la tarea educativa es una labor eminentemente social, y a través de la Ley pudo llegar especialmente a las clases menos pudientes en ese afán de ofrecer oportunidades a todos, misión básica de la política de aquel momento. En esta etapa hubo momentos difíciles. Los profesores se levantaron contra el Ministerio por cuestiones salariales, proyectaban una huelga con reuniones clandestinas... El Gobernador Civil me informó que iba a detener a los organizadores. Le pedi que me dejara intervenir; aceptó advirtiéndome de que si la gestión salía mal podía costarme el cargo. Les ofrecí la sala de reuniones de la Delegación garantizándoles su seguridad. Al final me entregaron sus conclusiones en un escrito dirigido al Ministro. $Y$ aquella gestión me reportó respeto y reconocimiento entre los docentes de la provincia. En otro orden de cosas, y gracias a la buena relación con los miembros de la Armada, pudimos suscribir un convenio para la cesión de terrenos en San Fernando donde construimos un gran complejo educativo que acabamos inaugurando en 1975, abierto a toda la población infantil, incluidos los hijos de marinos, sin distinción de clases ni categorías... Por su labor en esa provincia, la Academia San Romualdo de Ciencias, Letras y Artes de San Fernando le nombró Académico correspondiente.

En Cádiz permanece hasta que nuevamente regresa a Galicia en 1975 para ponerse al frente de la Delegación Provincial del MEC en A Coruña. Dejar Cádiz, La Tacita de Plata, la cultura andaluza en la que me había involucrado intensamente, separarme de sus gentes en unos momentos en los que ya todo era más fácil para mí, me produjo un sentimiento de tristeza que, sin embargo, no podía competir con la alegría de volver a Galicia, de reencontrarme con la familia, que seguía viviendo en Lugo; de recuperar a los amigos del ayer próximo... y acometer un nuevo reto, porque A Coruña era una provincia muy grande, de población muy diseminada y de configuración institucional compleja: Santiago de Compostela con la Universidad y el arzobispado; Ferrol, con la Capitanía General del Cantábrico; en verano, los consejos de ministros en Meirás, con la presencia de sus respectivos equipos ministeriales varios días... Por este motivo, los agostos en 
A Coruña eran una pesadilla para los Delegados de los Ministerios... [risas] Alguien me dijo al llegar: "Aquí no se permanece en los cargos: o te promueven, o cesas...». Las primeras declaraciones en la prensa local anunciaban lo que habría de ser su gestión: «No habrá en mi etapa navegación en solitario. Espero la colaboración y ayuda de las autoridades provinciales, alcaldes de las ciudades y los pueblos, instituciones, asociaciones de padres de familia, profesores y alumnos, porque la educación es misión social y solidaria». ${ }^{24}$

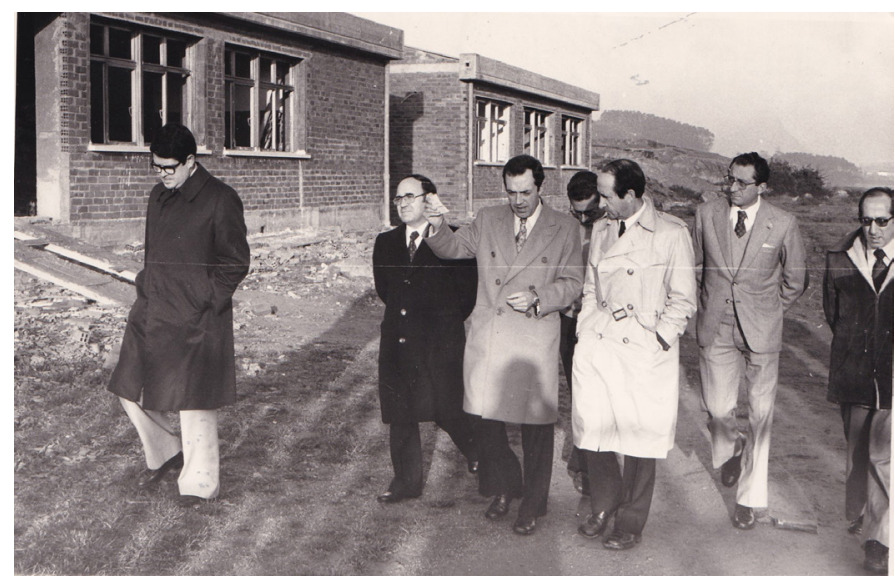

Imagen 5. A Coruña, 1976. Visita a obras de colegios en construcción con el alcalde de la ciudad José Manuel Liaño Flores.

En la Delegación Provincial, empecé a sustituir tabiques por mostradores abiertos para facilitar la comunicación con el público. Continuamos una labor muy importante en materia de construcciones escolares iniciada por mis predecesores, y elaboramos un nuevo mapa escolar que dio como resultado la construcción de más de treinta colegios e institutos politécnicos; paralelamente, la resolución por vía de urgencia de la escolaridad provisional en unidades prefabricadas, la ampliación de centros ya existentes, la adaptación de otros, la creación de bibliotecas públicas, que era el campo más yermo de Ministerio en la provincia... También se consiguió, en el ámbito del Patrimonio histórico-artístico, la declaración de zona monumental preservando toda la ciudad vieja de A Coruña, incluyendo la Marina, con el fin de salvarla de la especulación;

24 El Ferrol Diario, 14 de mayo de 1974. 
además de restaurar uno de los barrios más interesantes de Betanzos. ¡En A Coruña necesitaba días de cien horas! [risas]. En este sentido, fue muy importante la colaboración del consejero de Bellas Artes Manuel Chamoso Lamas.

En medio de toda esa actividad frenética, el 20 de noviembre fallece Franco... Son años difíciles, de alto voltaje político-social de transición a la democracia, del liderazgo del Presidente Suárez, de la coyuntura histórica de la Unión de Centro Democrático, de la ejemplar responsabilidad de los partidos políticos nacidos o recuperados, de los Pactos de la Moncloa, de la promulgación de la Constitución, de la transformación de la España centralizada en la España de las Autonomías... todo ello en el contexto de una crisis económica mundial. Permanezco en A Coruña ejerciendo de Delegado hasta que en el mes de diciembre de 1976 fui llamado a Madrid por Blat Gimeno, a la sazón Director General de Educación Básica, para ofrecerme el cargo de Subdirector General de Centros no Estatales por indicación del Ministro Aurelio Menéndez. Menéndez: "iTraiga al chico de La Coruña!». ${ }^{25}$ De la entrevista con el Ministro recuerdo que me agradeció el sacrificio de dejar una Delegación provincial tan importante y enfatizó mi experiencia profesional como inspector y titular en tres delegaciones provinciales. Me informó del nombramiento de mi nuevo Director General, D. Andrés Suárez, catedrático de la Universidad de León, y me pidió que le ayudara con todas mis fuerzas. Recuerdo que, finalmente, hizo un análisis de los cambios profundos que se estaban operando en España y de la oportunidad de incorporar a las nuevas generaciones a los cargos de responsabilidad. Al Ministro Menéndez, como a un par de antecesores más, los había conocido en el aeropuerto de Alvedro [A Coruña], a pie de escalerilla, con motivo del anual Consejo de Ministros agosteño de Meirás. En una recepción en el Hostal de los Reyes Católicos me di cuenta de que D. Aurelio Menéndez había dejado una huella profunda en su etapa de catedrático de la Universidad compostelana. Apenas podíamos caminar ante el acoso de sus numerosos exalumnos.

\footnotetext{
25 Para Aurelio Menéndez, Pedro Caselles era aquel «chico» que, en una recepción oficial en A Coruña, unos meses antes, y observando que su predecesor Carlos Robles Piquer, se encontraba fuera de escena, apoyado en una columna, completamente solo e ignorado, pidió licencia para acercarse y acompañarle. Un gesto de sensibilidad y elegancia institucional que no pasó desapercibido al Ministro.
} 
Había colegios en condiciones precarias que acabaron cerrando por cuestión de competitividad. Lo que hicimos fue reglamentar y clasificar para poder transformar y homologar, porque tanto el sector público como el privado estaban sirviendo a la sociedad en un mismo contexto novedoso

En enero de 1977, y hasta 1982, se abre una nueva etapa en su hoja de servicios en el primer gobierno democrático, con el citado ministro. En su nuevo cargo como subdirector general de Centros no Estatales, bajo las órdenes de Andrés Suárez, asumió la tarea de establecer convenios de colaboración con la red de centros privados, mayoritariamente congregaciones religiosas, para poder atender la necesidad urgente de escolarización ante la falta de una red pública de centros, en fase de construcción. Además, era necesario desmontar el recelo del sector privado ante su necesaria restructuración: Había colegios en condiciones precarias que acabaron cerrando por cuestión de competitividad. Lo que hicimos fue reglamentar y clasificar para poder transformar y homologar, porque tanto el sector público como el privado estaban sirviendo a la sociedad en un mismo contexto novedoso. Y en este sentido, aligerar con habilidad las presiones que en este momento de incertidumbre ejercía la Unión Nacional de Empresarios de Enseñanza no Estatal, urgiendo la implantación inmediata del régimen de conciertos previstos para los niveles de Educación Preescolar, Educación General Básica (EGB), Formación Profesional de $1 .^{\circ}$ grado, todo ello en base a hacer efectivo el derecho inalienable de las familias en cuanto a elección de centros en igualdad de oportunidades "y evitar una competencia perturbadora, que pone en peligro la existencia de nuestros centros y de los puestos de trabajo», como expresaba su Presidente, el sacerdote Ángel Martínez Fuentes, en la clausura de Congreso celebrado en Sevilla en abril de 1977.26

Pedro Caselles recuerda así aquellos primeros meses: Me gestionaron alojamiento provisional en la famosa Residencia de Estudiantes, en la calle Pinar. Fue una experiencia singular y estimulante por los excelentes residentes que conocí, por los encuentros emotivos con catedráticos de mis años de estudiante y por la emoción de vivir en el Olimpo de la intelectualidad española del pasado. Para colmo, mi Director General Andrés Suárez,

26 El Correo de Andalucía (16 de abril de 1977), 8. 
que dejaba en León esposa y familia numerosa, también se alojaba en la Residencia, lo que provocó una situación de entrega extraordinaria al trabajo, ya que Andrés acentuó mi asesoramiento en asuntos que competían a otras subdirecciones generales y a la Inspección General. Mi liberación se produjo a los pocos meses en que pude trasladarme a un apartamento próximo al Parque de El Retiro.

A pesar de la intensidad de las tareas y la entrega casi absoluta al cargo, en el breve tiempo que yo viví esa responsabilidad política, no recuerdo grandes conflictos por el choque de intereses con los centros privados. El carácter obligatorio de la nueva EGB y su gratuidad en los centros estatales fundamentado en el derecho a la escolaridad llevó a que se arbitrara un sistema de ayudas a los no estatales en función del interés social, de la demanda o del lugar de ubicación... Aunque todo dependió esencialmente del papel de cada delegado provincial. Recuerdo que, estando en Cádiz, recibi en algún momento una recomendación de Carrero Blanco, siendo Presidente del Gobierno, para que se diera una subvención al colegio de monjas al que iban sus nietas. Aquél, para el que se pedía subvención, era un colegio muy elitista; pero había otro de maristas en un barrio marginal que desarrollaba una función social muy necesaria. Yo le contesté que cumpliría sus órdenes, pero que se formaría un gran escándalo al haber otros colegios que debieran tener preferencia por tratar alumnado más humilde, etc. Me llamo su secretario: "Le agradece su sinceridad y que se olvide del tema» [risas]. En el tema de conciertos, durante esta etapa se desarrolló un trabajo interesante con la minoría gitana a través de las llamadas escuelas-puente. El pueblo gitano sufría mucho rechazo social, que todavía hoy no se ha resuelto del todo. En aquel momento había grupos infantiles desamparados, viviendo en zonas marginales de Barcelona, Madrid, Valencia, Zaragoza, Alicante... y sin acceso a la escuela pública. Suscribimos un convenio en 1980 con el Apostolado Gitano, dependiente de la Comisión Episcopal de Migraciones, y el Ministerio de Educación y Ciencia, por el cual éste nos cedió gratuitamente algunos de sus locales por diez años en los que instalamos unidades de EGB a través de las Delegaciones, haciéndonos cargo de los sueldos del personal docente, instalaciones, medios didácticos en régimen de administración general. Este convenio, como señaló más tarde, «ha dado frutos estimables en una estrategia de co-participación que no ha hecho más que empezar. Ciento cincuenta y siete unidades escolares, dotadas de profesorado especialmente escogido 
para impartir una educación adaptada; en otra vía, alrededor de mil niños cursan estudios en centros subvencionados». ${ }^{27}$

En el tema de los conciertos, hay que administrar la sensatez. A veces aciertas o te equivocas, o no te dejan... En ese sentido he procurado mantener la línea recta

Señalaba Antonio Viñao sobre este asunto en Revista de Educación que,

consecuencia necesaria de la obligatoriedad, [la LGE] conoció también un proceso de implantación, hoy [1992] todavía no concluido, lleno de problemas y diferencias. Su aplicación supuso la consolidación en este nivel educativo del sector privado de la enseñanza y el inicio del paso definitivo de sus gastos de amortización y funcionamiento a los presupuestos generales del Estado, por vía de las subvenciones primero y de los conciertos más tarde, con la llegada al poder del partido socialista y la aprobación en 1985 de la Ley Orgánica del Derecho a la Educación -aunque no esté de más recordar que, como en otros casos, el sistema de conciertos había sido el previsto y no aplicado por la Ley de 1970 en sus artículos 6.2, $94.4 b$ y 96 para los centros privados que recibieran subvenciones para la gratuidad. ${ }^{28}$

El de los conciertos -concluye Pedro Caselles-es un tema complejo. Hay centros que históricamente no hay quien los mueva. Por ejemplo, en Madrid: la parte baja de Chamberí, pegado a la Castellana, y el barrio de El Pilar. Hay alli una serie de colegios privados, pero ¿quien sustituye eso? Es imposible. Hay que ir a la expropiación con un costo de miles de millones, para acabar en lo mismo. Hay centros con tradición, consolidados sin posible sustitución o competencia cercana y esos fueron entrando en el número de conciertos. Recuerdo que, siendo Director General, le denegamos la subvención al famoso Colegio El Pilar, centro histórico de élite en el madrileño barrio de Salamanca, y por eso tuve algún conflicto, porque allí

27 Pedro Caselles Beltrán, «Prólogo», en Los gitanos. Problemas socioeducativos, Alfonso Iniesta (Madrid: Narcea, 1981), 14.

28 Antonio Viñao Frago, «La Educación General Básica. Entre la realidad y el mito». Revista de Educación n. ${ }^{\circ}$ ext. «La Ley General de Educación veinte años después» (1992): 54-55. 
estudiaban los hijos de amigos y de gente importante. Pero no se podía subvencionar colegios como aquél cuando habia necesidades en otros barrios desfavorecidos. De la misma forma que hubo que cerrar pequeños colegios privados, academias que no se ajustaban a las normas ministeriales o no reunían los mínimos de calidad exigidos... Me imagino que fueron víctimas de la novedad de una ley que vino a poner orden que, en muchos casos, implicaba su transformación con ayuda de créditos de interés social. Por otro lado, muchos centros religiosos, debido a la crisis de vocaciones, tuvieron que replantearse sus estructuras e instituciones docentes. En aquel momento era muy de agradecer que la iniciativa privada acudiese a las convocatorias públicas para cubrir plazas, aligerando la presión sobre el Ministerio que todavía carecía de los efectivos suficientes para atender las necesidades reales desde la oferta pública. Hay que administrar la sensatez. A veces aciertas o te equivocas, o no te dejan... En ese sentido he procurado mantener la línea recta....

En noviembre de 1977 fue nombrado Director General de Educación Básica del Ministerio, en sustitución de Andrés Suárez. Dirección General de la que dependía la educación de seis millones de niños y cerca de doscientos mil docentes, en un momento en el que estábamos esperando una nueva Constitución que iba a ser la que marcase las líneas de actuación. Y en este sentido, la Ley Orgánica por la que se regulaba el Estatuto de Centros Escolares (LOECE), promulgada posteriormente tras interminables debates de alta tensión dialéctica en el Congreso de los Diputados y en el Senado sobre los conceptos de "libertad de enseñanza», "participación en el gobierno de los centros», "escuela pública y privada», "ideario»... constituyó el primer banco de pruebas en la interpretación de la Carta Magna desde las distintas concepciones políticas.

Pedro Caselles ocupó la Dirección General durante los siguientes cinco años, en colaboración con Iñigo Cavero Lataillade (1977-1979), José Manuel Otero Novas (1979-1980), Juan Antonio Ortega y Díaz-Ambrona (1980-1981) y Federico Mayor Zaragoza (1981-1982). Trabajando estrechamente con estos cuatro ministros, aunque en algún caso de manera fugaz, esta es su impresión: Los ministros de Educación de los gobiernos de Unión de Centro Democrático (UCD), durante su mandato, comprendido entre 1976 y 1982, se aplicaron al desarrollo del artículo 27 de la Constitución en una delicada conjugación en el respeto a la Ley General de Educación. De todos ellos debo destacar su brillantez, su rigor intelectual y jurídico 
y su honradez. Buena prueba de ello es que en que sus trayectorias posteriores siguieron ocupando altas responsabilidades.

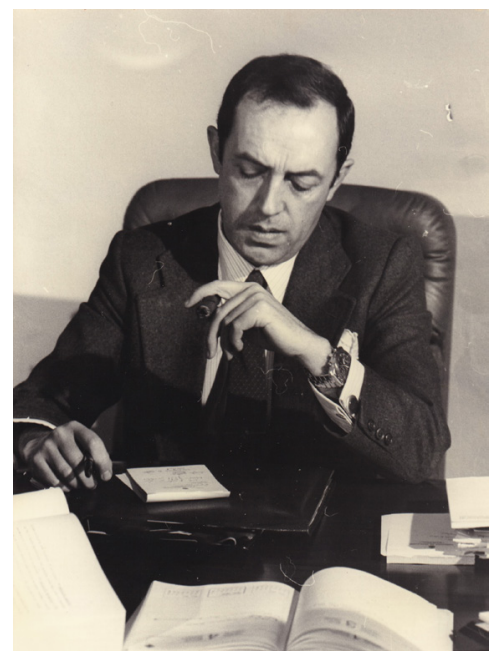

Imagen 6. Madrid, 1978. Pedro Caselles en su despacho del Ministerio de Educación.

Sobre cómo en el Ministerio se percibían las aspiraciones, preocupaciones y esperanzas de aquellos cerca de doscientos mil docentes, explica: Desde que me hice cargo de la Dirección General recibí ingentes cantidades de cartas de maestros y maestras en las que me manifestaban su confianza y su esperanza. Era una gran responsabilidad y al mismo tiempo un gran aliciente. En este ambiente, sobre el que se proyectaban tantas presiones y expectativas, Escuela Española se refería a Caselles como "un director general salido de la democracia», añadiendo: "Porque si una de las reivindicaciones de los maestros es tomar parte en la configuración de las grandes líneas de la política educativa, con Pedro Caselles podemos decir que un maestro ha sido llamado a las altas esferas de la Administración para representar los intereses de este nivel de enseñanza». ${ }^{29}$ En Magisterio Español, Menchu Rey escribía:

Es necesario poder dar respuesta a la sensación de olvido y minusvaloración que han sentido y sienten los profesores de Enseñanza General Básica. Es cierto que se ha superado aquello de

\footnotetext{
29 «La calidad, principal problema de la escuela. Declaraciones a Escuela Española del Director General de Educación Básica», Escuela Española (8 de marzo de 1978), 204-205.
} 
que "pasa más hambre que un maestro de escuela», pero todavía no tienen la valoración social, económica y profesional que se merecen los que tienen en sus manos el porvenir del país [...] Esperemos que Don Pedro Caselles pueda ser libre a la hora de adoptar soluciones fuertes como el estado de cosas actual demanda. ${ }^{30}$

Poco después, el Ministerio llegaba a un acuerdo con las centrales sindicales integradas en la comisión negociadora del profesorado estatal de EGB en relación con la implantación del complemento de dedicación exclusiva, que disfrutaban desde hacía tiempo otros cuerpos docentes. Un tema conflictivo que había dado lugar a una huelga en la que participaron cerca de noventa mil maestros y maestras: Llegamos a un buen acuerdo que vino a reglamentar el horario lectivo y no lectivo del profesorado, a retribuir con mayor racionalidad sus funciones y a dignificar, en definitiva, el trabajo docente de los profesores. Creo que fue un éxito transcendente, a pesar de la tensión que vivimos durante su tramitación y negociación. Se llevó a cabo también en este momento una considerable ampliación de plantilla por parte de la Dirección General de Personal que llevaba Matías Vallés. Otro aspecto que necesitada ser revisado era el del reciclaje y especialización del profesorado. Porque es cierto que se habia producido un cambio muy profundo sin hacer demasiadas previsiones. $Y$ en este sentido, una de mis obsesiones era conseguir la convocatoria de plazas por especialidades, desterrando el sistema de tradicional de provisión de vacantes por puntos acumulados, sin tener en cuenta el nivel de actualización y especialización a que hubiera podido llegar cada profesor.

En 1979 se crea el Centro Nacional de Educación Básica a Distancia, CENEBAD, un proyecto personal del Director General, que venía a complementar al Instituto Nacional de Bachillerato a Distancia, INBAD. Se encargaba de atender a la formación de adultos e incluso a aquellos alumnos de segunda etapa de EGB obligados a no asistir a clase por circunstancias diversas durante un periodo largo de tiempo, tratando de hacer posible el derecho constitucional a la educación de los ciudadanos, sea cual sean sus circunstancias personales; y cuya matricula fue aumentando considerablemente en número y dispersión nacional e internacional hasta llegar a atender alumnado de 46 países, además del 34 por ciento

\footnotetext{
30 Menchu Rey, «Momento de decisiones», Magisterio Español, 11 de noviembre de 1977.
} 
de la población reclusa. ${ }^{31}$ Otro reto importante de esta etapa fue también la Educación Permanente de Alumnos. La EPA fue, efectivamente, otra de las tremendas batallas libradas desde la Dirección General. Conseguimos abrir brecha, con algún esfuerzo, pero creo que dio un resultado espectacular, gracias a que se configuraron diversos procedimientos en paralelo para adaptarnos a la situación de los alumnos y a la peculiaridad de las distintas localidades. Hay que tener en cuenta que hubo centros especificos dedicados en exclusiva a la EPA, con profesores especializados como en otras modalidades. En el año 1985, el Ministerio de Educación ofrecía unas cifras «sobrecogedoras», en opinión del diario $A B C$ : «más de dos millones de analfabetos absolutos y nueve millones y medio de españoles que, aun sabiendo leer y escribir, manejan con gran dificultad el lenguaje escrito». ${ }^{32}$

Los Programas renovados nacen a raíz de algunos errores en la aplicación y desarrollo de la LGE. Habían pasado ya más de diez años de su implantación, que había aportado como novedad la creación de un tronco común de estudios para todos los niños españoles desde los seis a los catorce años

El 19 de junio de 1980 se promulga la Ley Orgánica por la que se regula el Estatuto de Centros Escolares, LOECE, cuya Disposición final segunda derogaba varios artículos de la LGE. Pedro Caselles enumeraba en Escuela Española algunos de sus principios:

Desde el punto de vista político, destaca la implantación sólida de los principios de libertad, participación y elección en el funcionamiento de los centros; desde una perspectiva técnica, la superación del sistema de promoción automática de los alumnos, causa de tantos fracasos escolares. Por otro lado, la ruptura de la rigidez vigente en la estructuración de los centros, posibilita un acercamiento de los mismos a las localidades en donde residen los alumnos. ${ }^{33}$

\footnotetext{
$31 A B C$ (8 de enero de 1985), 42.

$32 A B C$ (8 de enero de 1985), 42.

33 «Pedro Caselles, Director General de EGB a ESCUELA ESPAÑOLA. La calidad de la enseñanza, un objetivo global y progresivo», Escuela Española (12 de junio de 1980), 2.
} 


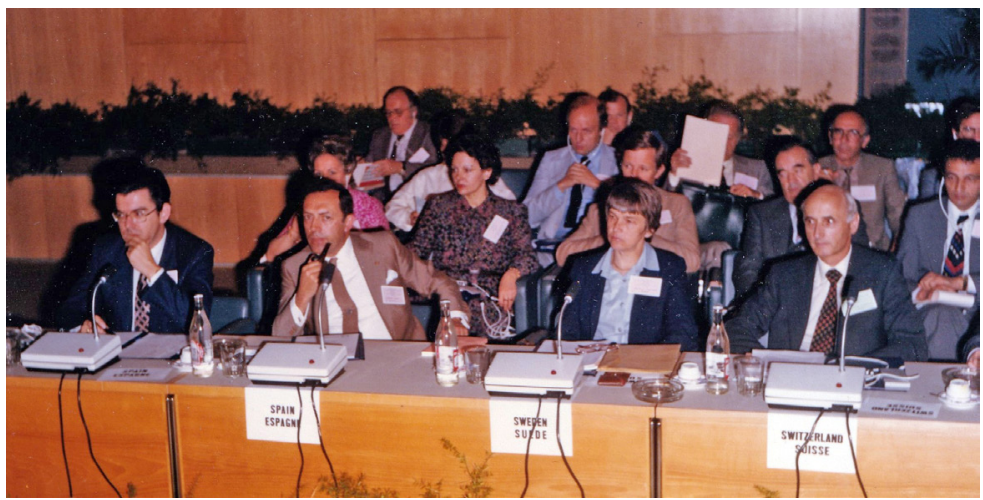

Imagen 7. Lisboa, 1981. Conferencia de Ministros de Educación.

Y anticipaba una profunda renovación de los Programas para la EGB, poniendo un acento especial en la relación de la escuela con el entorno social de la misma y, en esa misma dirección, con la consideración de las regiones y de las autonomías... Sobre este asunto, nos aclara: Los Programas renovados nacen a raíz de algunos errores en la aplicación y desarrollo de la LGE. Habian pasado ya más de diez años de su implantación, que habia aportado como novedad la creación de un tronco común de estudios para todos los niños españoles desde los seis a los catorce años. Pero no solo eso. Las orientaciones que inspiraron la puesta en práctica de la EGB contenían una serie de principios pedagógicos innovadores y valiosos que estuvieron vigentes durante mucho tiempo vivificando y renovando la práctica escolar. Pero hubo que reconocer que no se alcanzaron las cotas de rendimiento que serían deseables en un nivel de escolaridad general y obligatorio. De este modo, la reforma de los contenidos de la EGB se hizo atendiendo a las numerosas insuficiencias que tenía la Ley, que pudimos conocer por los trabajos realizados por la comisión de evaluación y la Inspección Central de $E G B$, a los que se sumaron los informes de los inspectores, las protestas del profesorado y las quejas de las familias. Estas deficiencias estaban relacionadas con el aprendizaje de las materias instrumentales-lectura, escritura y cálculo-sobre las que se construye el aprendizaje de todos los contenidos posteriores; también con las orientaciones pedagógicas, pues eran demasiado generales en su formulación y carecían de concreción de objetivos, lo que condujo a un pluralismo interpretativo en los libros de texto, que fue un foco de problemas para los alumnos; y la supresión de la promoción automática, sustituida por un control que se establecía al final del ciclo. 
En cuanto al profesorado, no se estaba utilizando de una forma eficaz su especialización debido a una inadecuada provisión de los puestos de trabajo, y existía una enorme movilidad, lo que tratamos de corregir en su momento, procurando que un mismo docente, al que denominamos profesor de ciclo permaneciera en el ciclo completo, lo que le posibilitaba un conocimiento profundo de todo su alumnado y facilitaba una más exacta evaluación de su rendimiento. En este sentido, uno de los principales objetivos de la nueva programación se centraba en elevar el nivel de calidad de la educación, difícil de alcanzar si a pesar de disponer de unos programas muy buenos no se contaba también con el profesorado adecuado, de forma que no sucediera como hasta entonces, que un especialista en matemáticas estaba impartiendo inglés y uno de sociales impartía matemáticas. Lo que tratamos fue fijar la plantilla de los centros, fijar las especializaciones que tenía que haber en ellos e imponer el criterio decisivo de que para desempeñar una especialidad había que ser un especialista. Además, hacían falta instrumentos de apoyo a la actividad didáctica que se pretendía renovadora, con el objeto de que las normas escritas fueran la partitura nada más, aunque nada menos, y era a los profesores a quienes les correspondía interpretarla y ejecutarla armonizando una orquesta en la que participaban más de seis millones y medio de alumnos y ciento noventa mil profesores de EGB.

En su conjunto, la LGE supuso un programa de modificaciones que, a juicio de Antón Costa, resultaron insuficientes

en medio de los abultados cambios sociológicos, económicos y culturales que comenzaba a vivir la sociedad española. Se registra una fuerte imprevisión ante las demandas sociales de educación de los amplios sectores populares, que se atiende con un desordenado aumento de la escolarización que no tiene en cuenta un diagnóstico correcto de las necesidades formativas de los diversos sectores de la población, ni de la geografía regional española y de sus características culturales; se favorece, además, la constitución o solidificación de un notable sector de centros privados, que se viene a sumar a la oferta tradicional privada católica, en condiciones infraestructurales y de servicio, por lo general, de limitada calidad. ${ }^{34}$

\footnotetext{
34 Antón Costa Rico, «Conflito social e construción da educación democrática en España. Entre o Franquismo e as Reformas Socialdemócratas», en Educaçâo, Historia e Políticas. Tributo a Rogério Fernandes, coord. Fernando Cabral Pinto (Lisboa: Ediçôes Piaget, 2015), 137-182.
} 
Por su parte, Pedro Caselles reiteraba en Razón y Fe que todo el «corpus» normativo en materia educativa tenía su raíz y su asiento en la LGE de 1970, "una ley de reconocida ambición innovadora, probado perfeccionismo técnico, hondo contenido social y clara vocación anticipatoria respecto del tiempo y el contexto político en que nació».35 $\mathrm{Sin}$ embargo, puntualiza, habia una serie de cuestiones que necesitaban una profunda reflexión y revisión, pues en su conjunto se revelaban como causas del elevado índice de fracaso escolar, más de un 30\%, al terminar la EGB. De todos modos, matiza, el tema del fracaso escolar fue algo que se puso muy de moda en la prensa de la época y que normalmente se trataba con una enorme frivolidad. En el mal llamado fracaso escolar y en el retraso escolar que es cosa distinta, inciden numerosas causas inherentes al propio sujeto, al profesorado, al entorno y al sistema. Las situaciones socio-familiares son distintas y hasta el mismo punto de arranque en el sistema es diverso, ya que, en ese momento, unos partían con el Preescolar y otros no, lo cual realmente era injusto. Muchas de las críticas que se hacen a la escuela, a la educación, no son imputables a ella, que no es más que un subsistema dentro del sistema más amplio que constituye la propia sociedad. Así, la escuela paralela de la que nuestros hijos y jóvenes obtienen una parte importante de sus conocimientos, puede influir positiva o negativamente, según cual sea su enfoque y orientación. En todo caso, la cultura resultante será siempre una cultura- mosaico, incoherente, que precisa ser sistematizada en la escuela para que se convierta realmente en cultura.

\section{En la década de los 80 fracasaban muchos menos niños y niñas que en la década anterior, porque entonces no se les daba la posibilidad de fracasar más que a los hijos de los ricos, o a unos pocos que estaban en una situación de privilegio}

Mi opinión es que en la década de los 80 fracasaban muchos menos niños y niñas que en la década anterior, porque entonces no se les daba la posibilidad de fracasar más que a los hijos de los ricos, o a unos pocos que podían acceder a una beca, es decir, a los que estaban en una situación de privilegio. Los demás, en áreas urbanas desfavorecidas o del medio rural,

\footnotetext{
35 Pedro Caselles Beltrán, «Ley de Ordenación General del Sistema Educativo (LOGSE)», Razón y Fe. Revista Hispanoamericana de Cultura 233 (1996): 262.
} 
de donde yo provengo, se iban a segar o a cuidar vacas. Antiguamente, solo se podía estudiar hasta los diez años, unos pocos iban a los colegios privados o a las preparatorias de los institutos, que había uno en cada capital de provincia... Con la Ley Villar era evidente que promocionaba mucha más gente que en décadas anteriores, se incorporó a la escolaridad mucho más alumnado y por eso habia, porcentualmente, una mayor visibilidad del fracaso... Por otro lado, como repeti en numerosas ocasiones y comparecencias públicas siendo Director General, los Programas renovados eran un instrumento valioso, pero no el único, para mejorar la calidad de la enseñanza en aquel momento. Estaba la cuestión económica, con la necesidad de elevar cinco puntos, al menos, el presupuesto de enseñanza, y también la técnica. Me refiero concretamente a los criterios que determinaban el acceso del profesorado a unos niveles $u$ otros, entre los que seguían prevaleciendo los de la antigüedad por encima de los profesionales, como el de la especialización en un área o materia concreta.

Pedro Caselles fue promotor y responsable directo de la reforma de la Educación Preescolar y Educación General Básica:

Los sistemas educativos exigen una revisión periódica en función de la aceleración histórica, los avances científicos, la globalización del saber y la aplicación correcta de las nuevas tecnologías. Evaluar y reformar la educación constituye un reto permanente y una responsabilidad compatible con intereses y ópticas plurales. Ser hoy y construir el mañana, o fosilizarnos. Ésa es la cuestión. ${ }^{36}$

«El hombre de la Reforma de la EGB», como lo definía Vida Escolar en 1982,37 tenía como uno de sus objetivos introducir en los centros educativos los valores democráticos consagrados en la Constitución Española de 1978, que dio como resultado la promulgación de numerosas disposiciones en forma de Reales Decretos y Órdenes Ministeriales entre los años 1978 y 1982: La escuela no podía ser ajena a los profundos cambios politicos que se estaban produciendo en los últimos años. Franco habia muerto, España había cambiado de régimen dando origen a una nueva Constitución, que debería ser materia de estudio y conocimiento;

\footnotetext{
36 Pedro Caselles Beltrán, «Ser hoy y construir el mañana, o fosilizarnos. Ésa es la cuestión», en 25 años de educación en España, VV. AA. (Madrid: Editorial Santilla, 2003), 29.

37 Antonio Molina Armenteros, «Entrevista. Pedro Caselles, Director General de Educación Básica. El hombre de la Reforma en EGB», Vida Escolar 220-221 (1982): 3.
} 
además, porque los principios que la sustentaban habian de ser también los principios inspiradores de toda labor educativa. Pero como también manifesté en diversas ocasiones, la escuela tiene que enseñar fundamentalmente a vivir y a convivir. Tratar de imponerla a palo seco hubiera sido absolutamente contraproducente, porque caeríamos otra vez en la Formación del Espíritu Nacional ${ }^{38}$ e iría contra las leyes del aprendizaje y los escolares acabarían odiándola.

El 30 de junio de 1980 publica una entusiasta "Carta Abierta», que encabezaba en la revista Vida Escolar el Documento Base de los Programas Renovados. Independientemente de su divulgación en los medios, el Documento Base fue presentado en todas las provincias por los coautores, Subdirector General y Director General. Se celebraron coloquios abiertos en los salones con más capacidad con petición de aportaciones. Era el resultado de tres años de intenso trabajo desarrollado por un grupo de inspectores acompañados por cerca de cuatrocientos especialistas, en su mayor parte profesorado en ejercicio. ${ }^{39}$ En ella habla de la necesidad de un nuevo impulso:

Enraizar la escuela en la realidad, hacerla permeable a la vida, potenciarla para que pueda dar respuesta a los interrogantes que se le plantea a nuestros alumnos cada día. La Educación Básica debe formar en la vida y para la vida, ayudar en el arriesgado difícil empeño de aprender a vivir y a convivir en un tiempo en el que el hombre necesita, más que nunca, poseer la fuerza del equilibrio personal para proyectarse como constructor de un mundo en justicia y paz. La escuela no puede ser fábrica de

\footnotetext{
38 Asignatura obligatoria que se cursaba en el Bachillerato durante el franquismo. Formación del Espíritu Nacional (FEN) tenía por objeto aleccionar en los valores nacional-católicos que se identificaban con el Movimiento Nacional.

39 Véase: VV. AA., Los Programas renovados de la EGB Análisis, crítica y alternativas (Madrid, ICE/ UAM: 1981), que recoge los trabajos presentados en las «Jornadas para en estudio de los Programas Renovados de la E.G.B», organizadas por el ICE de la Universidad Autónoma de Madrid, celebradas los días 21, 22 y 23 de mayo de 1981, cuyo objetivo era «evaluar los Programas Renovados, examinar la forma de obtener el máximo partido de ellos, compararlos con las Orientaciones pedagógicas de 1970 vigentes hasta ahora y elevar sugerencias al Ministerio respecto al Ciclo Medio y Superior que están en período de ensayo y consulta», contando con la participación de "profesores de EGB, de bachillerato y de la Universidad, inspectores, pedagogos, psicólogos, padres y representantes de asociaciones de padres, directores de centros escolares, autores y editores de libros de texto, responsables de educación en las comunidades autónomas, personas que han contribuido a la elaboración de los programas, así como otros funcionarios ministeriales».
} 
alienaciones ni taller de pasotismo; cauce de aburrimientos o fuente de fracasos; la escuela debe sembrar ilusión, inculcar valores, ser trampolín de futuro.40

Cuando Pedro Caselles se involucra en los Programas Renovados es a raíz de su ascenso a la Dirección General de Educación Básica, a propuesta de Íñigo Cavero, ya que yo venía desempeñando durante unos meses la Subdirección General de Centros no Estatales con Aurelio Menéndez. Cavero me llama una noche para ofrecerme el cargo. Recuerdo que, en la puerta del ascensor, al despedirme, me dijo dos cosas: "Vete mañana a un fotógrafo de estudio, que te haga una foto bonita porque vas a salir mucho en todos los periódicos» [risas]... Y con la puerta abierta del ascensor añadió: "Bueno, yo no te he preguntado políticamente qué es lo que piensas... ¿Cómo nosotros, más o menos?». "Me imagino que sí - le contesté como buen gallego - estamos en la Transición... estamos en el cambio, en la España nueva... la vinculación de las nuevas generaciones con la modernidad...». Una de las primeras cosas que hice fue revisar el equipo que yo heredaba, y me pareció que era un grupo de hombres beneméritos, pero ya mayores, con un historial franquista de toda la vida. Era necesario introducir personas con una nueva visión, viendo más al futuro que al pasado. $Y$ entonces nombré a María Teresa López del Castillo para la Subdirección General de Orientación Educativa [SGOE]. Una mujer de una gran preparación; ella fue la persona que se encargó de este tema. Porque creo que el secreto para hacer una labor eficaz consiste en trabajar en equipo, estar rodeado de personas capacitadas y responsables, como era el caso de María Teresa; dedicarle muchas horas y mucho sacrificio y vivir el tema desde dentro, porque la responsabilidad, la función, se convierte en misión cuando se desempeña con cariño, con pasión incluso. Por eso, en esta «Introducción» de Escuela Española trato de animar a los maestros en un lenguaje emotivo, también en cierto modo entusiasta, que era necesario contagiar a través de las Inspecciones y los Centros de colaboración pedagógica de las zonas. María Teresa López del Castillo llegaría a escribir algunos años más tarde recordando aquella etapa:

Pedro Caselles me propuso ocupar la SGOE que dejó vacante Ana M. ${ }^{a}$ García Armendáriz [...]. Aquel fue el trabajo más

40 Pedro Caselles Beltrán, «Carta abierta del Director General de Educación Básica», Vida Escolar 206 (1980): 2 (Documento Base. Programas Renovados de la EGB Separata). 
interesante de toda mi carrera. Además de que el trabajo fue muy agradable por el perfecto entendimiento que alcancé con Pedro Caselles, que fue un excelente jefe sin dejar de ser compañero, se había establecido una forma de trabajo por objetivos, de cuyo cumplimiento dábamos cuenta periódicamente teniendo por lo demás amplia libertad para organizarnos en la forma que estimáramos oportuna. Solo recuerdo dos aspectos negativos: uno de ellos fue el continuo cambio de Ministros y de equipos ministeriales con la inestabilidad que representaba para la Administración, si bien es verdad que al menos en nuestra Dirección General el trabajo jamás se "paralizó», ni siquiera se ralentizó por este motivo. Nuestros proyectos tuvieron una total continuidad a lo largo de cuatro años en que desfilaron por el Ministerio Íñigo Cavero, Manuel Otero Novas, Juan Antonio Ortega Díaz Ambrona y Federico Mayor Zaragoza. ${ }^{41}$

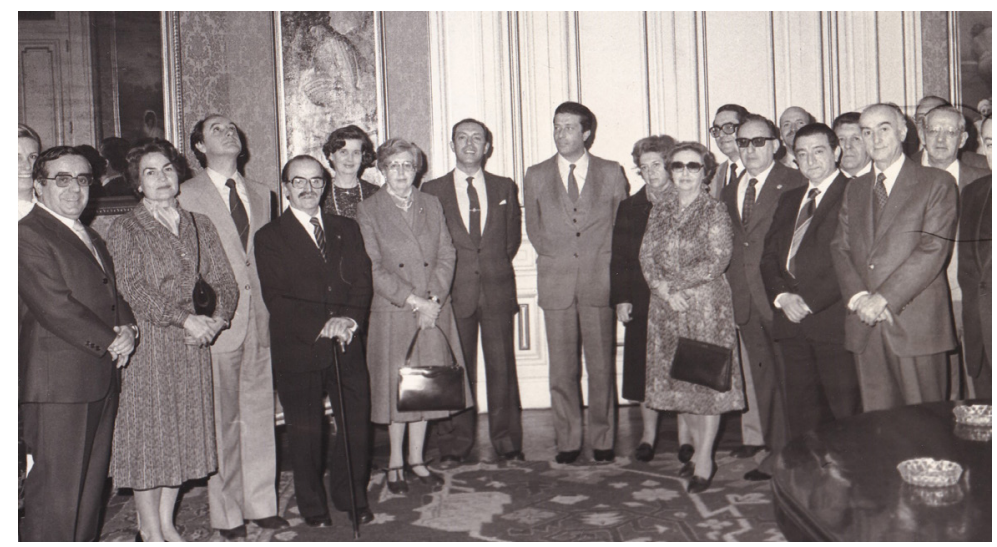

Imagen 8. Madrid, 1982. Con Federico Mayor Zaragoza, M. ${ }^{a}$ Teresa López del Castillo y miembros de la inspección central en la recepción de la promoción de Inspectores Técnicos de Educación de 1956.

Sobre la renovación de los Programas, M. ${ }^{\mathrm{a}}$ Teresa López de Castillo añade:

pretendían ser prácticos, orientadores para la actividad del aula. No aspirábamos a dar lecciones de psicología, ni siquiera de

${ }^{41}$ M. a Teresa López del Castillo, «La inspección que he vivido», 295. 
pedagogía. Creíamos que la psicología y la pedagogía debían estar implícitas en la formulación de los objetivos, contenidos y actividades. Teníamos miedo al ampuloso discurso pedagógico que, por no conectar con la realidad de los centros, había conducido a tantos dislates en la educación general básica. Pero ¡ya lo creo que eran renovadores! Por primera vez se eliminaba la gramática del Ciclo Inicial, y se centraba la enseñanza en la práctica de la lengua; por primera vez se enfocaban las ciencias sociales y naturales partiendo del estudio y observación del medio; y por primera vez se introducía la educación para la salud, la educación vial, la educación para el consumo, es decir, lo que ahora se llaman «materias trasversales» y que entonces denominábamos «objetivos sectoriales».42

Sostiene Pedro Caselles que, pese a la suma de frustraciones, omisiones y excesos en que se haya podido incurrir durante su proceso de aplicación, en realidad, me atrevo a destacar entre los logros de la Ley Villar, el de ser la revolución educativa más importante de nuestra historia de la educación, con la extensión de la enseñanza obligatoria hasta los catorce años - que Raúl Vázquez quiso, en algún momento, ampliar hasta los dieciséis -; miles de sórdidas escuelas fueron sustituidas por modernos colegios: cientos de miles de nuevas aulas, de nuevos equipos con la construcción masiva de centros completos. Se llevó a cabo la reforma estructural de la educación, con la sustitución paulatina de la escuela unitaria y mixta por la escuela graduada. Se elevó el estatus académico de los maestros mediante el perfeccionamiento de su formación inicial y especialización: el antiguo maestro nacional pasó de ser bachiller elemental a titulado medio y, posteriormente, universitario de grado medio. Se promovió el crecimiento espectacular de su plantilla y del personal de administración y servicios... Es decir, con Villar Palasí se llevó a cabo un enorme avance en el sistema educativo.

Volviendo a la renovación de los Programas, era necesario explicarla por el profundo cambio socio-político operado en España después de diez. años de la implantación de la EGB; por la evaluación de las tasas de fracaso escolar y el análisis de sus causas; por las nuevas demandas sociales o el envejecimiento de los contenidos. Y, además, por la necesidad de una

42 López del Castillo, «La inspección que he vivido», 297. 
renovación pedagógica profunda para un nuevo contexto de civilidad democrática y modernidad social, donde se incorporaban nuevos contenidos en áreas tan necesarias como eran la educación para la convivencia, la seguridad vial, la iniciación a la práctica de las tecnologías básicas, la conservación y mejora del medio ambiente físico y social, o un tema que nos pareció muy importante, como fue la educación para la salud, la medicina y la higiene escolar. Otra cuestión que consideramos esencial fue la de vincular educación y empleabilidad, y con este fin se firmó el convenio entre la Dirección de Educación Básica y el Instituto de Empleo, con el objeto de realizar una actuación coordinada entre el mundo del trabajo y el de la educación para facilitar el intercambio de información sobre el mercado laboral y ocupaciones profesionales, y la referida a aspectos académicos de interés para la formación de los trabajadores.

En realidad, cuando se montan unos programas nuevos de educación, todo el mundo quiere plantar su árbol en ese huerto. Yo recibí muchas presiones, desde almirantes... -recuerdo un tema que se propuso, que yo acepté, relacionado con el mar y las marinas: mercante, de guerra, pesquera, deportiva...-, y algunas recomendaciones, como la del Presidente de UNICEF, para la inclusión de contenidos educativos sobre la comprensión de la paz y la solidaridad internacional. Era información novedosa e interesante... Otros, por el contrario, nos pedian otras cosas que no aceptamos.

Pero los denominados Programas renovados, en cuya elaboración se dio participación a muchos profesores, se llevaron a consulta pública a través de Vida Escolar, se consultó administrativamente a las Comunidades Autónomas y el texto final fue sometido a los dictámenes del Consejo Nacional de Educación y del Consejo de Estado. Se aprobaron ya en una etapa de transición política... Era un botín de caza muy interesante para ser utilizado por el PSOE y se notaba una cierta contrariedad en que, un régimen que ya sabiamos que iba a caer, antes o después, por aquel enorme desgaste político de la UCD, pudiera sacarlo adelante. Ahí arranca también la etapa más amarga que es la de José María Maravall, con la famosa Ley de Función Pública y la abolición de todas las escalas - catedráticos, inspectores, etc. -; algunos persistimos, llegamos al Tribunal Supremo, y nos ofrecieron la posibilidad de quedar en el cuerpo activo, que no era un cuerpo franquista, pues databa de 1849, con Bravo Murillo.... 
Sobre este asunto, Blat Gimeno escribía en $A B C$ en 1984:

La inspección española tiene una fecunda tradición de servicio a la educación, especialmente desde la creación en 1909 de la Escuela de Estudios Superiores del Magisterio, para la formación de Profesores de Escuelas Normales e Inspectores y de la que fueron profesores personalidades tan destacadas como Ortega y Gasset, García Morente, María de Maeztu, Rogelio Sánchez, Rufino Blanco, Zulueta y Barnés. Es fácilmente imaginable la extrañeza que produciría en tan eminentes catedráticos, así como en los ministros de la República, Fernando de los Ríos, socialista; Marcelino Domingo y Domingo Barnés, radicales socialistas, que tan decidida colaboración tuvieron de la inspección en sus planes educativos, si contemplasen ahora la extinción a plazo fijo, a propuesta de los correligionarios del cuerpo que ellos consideraban fundamental para la aplicación de sus políticas educativas. ${ }^{43}$

Más tarde, en 1989, Adolfo Maíllo también escribió lo siguiente:

La muerte anunciada de la Inspección procedente de la etapa política anterior al gobierno socialista, además de originar sufrimientos morales invaluables (por tratarse de bienes no venales), degradó y recortó sus funciones durante cinco años (1984-1989) empleándoles en tareas tan «humildes» como llevar y traer recados a los colegios, siempre en parejas, como la Guardia Civil, por si no bastaba uno solo para tan complicado menester, propio de cualquier alguacil de pueblo. ¿No se dio cuenta la Administración (¿educativa?), de que había puesto en ridículo a la Inspección de E.G.B, único Cuerpo superior de funcionarios del Estado que accede al desempeño de sus funciones por concurso, agravio comparativo que supone una capitis diminutio para el que fue, desde fecha secular, Cuerpo en el que se ingresaba por oposición?44

Con respecto a las relaciones con la Conferencia Episcopal desde el Ministerio, durante esta etapa de Transición, Pedro Caselles recuerda:

\footnotetext{
43 José Blat Gimeno, «La supresión de las inspecciones, una grave amenaza», $A B C, 12$ de junio de 1984.

44 Adolfo Maíllo García, Historia crítica de la Inspección escolar en España (Madrid: Josmar, 1989), 379.
} 
Bueno, eso es materia reservada, me imagino... [risas]. Sí, tuve una colisión siendo Ministro Federico Mayor Zaragoza, cuando Elías Yanes, a la sazón Presidente, nos propone convertir en funcionarios a los curas que eran profesores de religión. Yo me negué, dije que eso no podía ser, porque si esos curas -en un momento especialmente delicado en que muchos de ellos se habian pasado a organizaciones políticas alejadas de la ortodoxia católica-, siendo profesores de religión, mañana se ponen a apostatar... ahora los pueden cesar, porque son nombrados por ustedes, y aceptados por nosotros. Pero si los hacemos funcionarios, yo no los puedo echar... Además, entraba en colisión frontal con el derecho a la libertad de cátedra. Entonces cambiaron de interlocutor, y nos mandaron a Antonio María Rouco Varela, y en esa entrevista estaba conmigo Raúl Vázquez -los tres gallegos-, y Rouco lo entendió enseguida... En otro momento, recuerdo, cuando decidimos incorporar la educación sexual en la escuela, y acabar con los mitos de las cigüeñas, ya en los Programas Renovados, curándome en salud sin consultar a la Conferencia Episcopal para que no me cortaran la cabeza... [risas] Y se lo razonamos: había que pasar del mito, pues vivíamos ya unos tiempos en los que habia que conciliar la fe con la ciencia. En la Conferencia Episcopal me lo aceptaron con mucha prudencia. Naturalmente no me contestaron por escrito...

Anteriormente, pude hacer un gran convenio con Ángel Suquía en Santiago de Compostela - una persona dialogante, abierta y dotada de una gran sensibilidad social- , cuando ocupamos el monasterio de San Martín Pinario, y el edificio anejo a la colegiata del Sar, que estaban vacíos, y montamos allí sendos colegios de EGB, con toda la obra civil de adaptación con cargo al Ministerio de Educación hasta que pudiéramos resolver la situación definitiva de las construcciones. En ese campo de gestiones con obispos, con los que se negociaban acuerdos de solares para colegios, para resolver problemas de escolarización, siempre tuvimos una buena relación.

Las nuevas orientaciones pedagógicas y administrativas que requerían la implantación de la EGB y la reestructuración de los contenidos en ciclos, significaron un cambio fundamental en la concepción de la enseñanza elemental, y del manual escolar como una de sus herramientas tradicionales de trabajo. De este modo, como señala Agustín Escolano,

la nueva generación de libros escolares ha transformado los modos de producción, comercio y consumo de manuales didácticos. [...] Ella ha propiciado un verdadero boom en el mundo de la 
edición escolar, induciendo el declive de las casas editoriales asociadas a la primera generación de textos, que en su mayor parte desaparecen de la escena comercial, y la aparición de las nuevas empresas que van a liderar el sector desde entonces hasta la actualidad (Anaya, Santillana, Vicens Vives, SM, Everest...). De los grupos anteriores sólo sobreviven aquellos que, como Edelvives o Bruño, cubren circuitos corporativos (en este caso de congregaciones religiosas). Se afirman igualmente en este proceso, con sus cuotas periféricas, algunas editoriales cuyo círculo de influencia se define en mercados notoriamente territorializados o regionales. [...] La expansión de estos grupos ha inducido su proyección hacia otros sectores del mundo de la comunicación y las empresas mediáticas, lo que, por primera vez en la historia de la escuela, ha venido a vincular a esta industria de la cultura con ámbitos más generales de la economía y de la sociedad. ${ }^{45}$

Un proceso que ya se había iniciado en 1965, cuando se modernizan los Cuestionarios programáticos de enseñanza primaria y se autorizan cientos de nuevos libros de texto y obras complementarias para su uso en las escuelas primarias, y se extiende de modo omnímodo el poder de los libros de texto (y de las fichas de individualización de la enseñanza), que condicionarán el modelo de cultura escolar, con sus pautas planificadas, programadas y así organizadas. ${ }^{46}$

\section{En lo que se refiere a la transformación del mundo editorial, y a las} relaciones de los grandes grupos con el Ministerio, desde la Alta Inspección del Estado se ejerció el control oportuno para garantizar que los libros de texto y demás material didáctico se adecuaran a las enseñanzas mínimas que integraban el currículo estatal

Hubo, en consecuencia, la necesidad de adaptarse a las exigencias de la nueva orientación de la EGB relacionadas con «los principios didácticos, la estructura y el contenido de la nueva orientación» (BOE, 8

\footnotetext{
45 Agustín Escolano Benito, «La segunda generación de manuales escolares», en Historia ilustrada del libro escolar en España, Volumen II: «De la posguerra a la reforma educativa», dir. Agustín Escolano Benito (Madrid: Fundación Sánchez Ruipérez, 1998), 32-33.

46 Antón Costa Rico, «Conflito social e construción da educación democrática en España. Entre o Franquismo e as Reformas Socialdemócratas», 137-182.
} 
de diciembre de 1970), pero también con la renovación de los géneros, los diseños, la iconografía... de tal modo, que el libro de texto en un nuevo formato acaba por adquirir una relevancia central en la práctica educativa de ese momento... Sobre este aspecto, Pedro Caselles aclara: La implantación de la LGE no alteró sustancialmente la política franquista caracterizada por la previa autorización de los manuales antes de ser comercializados. Con la renovación de los Programas, se incorporaron una serie de consejos para la confección de los futuros libros de texto. En lo que se refiere a la transformación del mundo editorial, y a las relaciones de los grandes grupos con el Ministerio, desde la Alta Inspección del Estado se ejerció el control oportuno para garantizar que los libros de texto y demás material didáctico se adecuaran a las enseñanzas minimas que integraban el currículo estatal. Y como es natural, siempre hubo presiones de las grandes editoriales, sobre todo en la etapa de incorporación de los Programas Renovados en la que se nos exigía mayor libertad de expresión a la hora de redactar los contenidos y se nos acusó de cierta improvisación y de las dificultades técnicas que planteaba el recién estrenado Estado de las Autonomías. Yo me reunía periódicamente con los miembros de la Asociación Nacional de Editores de Libros de Enseñanza (ANELE), pero me reunía con todos a la vez, para tratar de ofrecer la mayor transparencia en asuntos delicados, como la supervisión de los contenidos o la fijación de precios para el control de márgenes comerciales en un producto, como era y sigue siendo, de primera necesidad.

Durante esta etapa, la labor de Pedro Caselles Beltrán en el Ministerio es reconocida con varios galardones: recibe la Medalla de oro de Servicios al Magisterio Español, la Insignia de oro con distintivo blanco en reconocimiento a su labor en la Educación General Básica en España; la Medalla al Mérito de la Seguridad Vial con distintivo azul, categoría de Plata otorgada por el Ministerio del Interior y la Medalla Año Internacional del Niño de UNICEF. El trabajo de Director General de Educación Básica, explicaba en Vida escolar, «es muy poco conocido y valorado. El tener una clientela de seis o siete millones de alumnos, con sus padres, familiares, profesores, autoridades locales, etc., dan una configuración muy compleja y muy singular a este puesto de servicio a la sociedad».47

47 Antonio Molina Armenteros, «Entrevista. Pedro Caselles, Director General de Educación Básica. El hombre de la Reforma en EGB», Vida Escolar 220-221 (1982): 4. 


\section{Cuando aceptas un cargo de confianza, después tienes que saber marcharte con dignidad}

Con la llegada del PSOE al poder, Pedro Caselles pone su cargo a disposición del nuevo gobierno: Cuando aceptas un cargo de confianza, después tienes que saber marcharte con dignidad. Aunque tuve que permanecer en la Dirección General algunos meses, a petición del Ministro Maravall, hasta encontrarme un sustituto. Esa persona fue Blanca Guelbenzu Valdés. A partir de ese momento, y entre 1982-1983, desempeñó labores de inspección educativa, en comisión de servicios, en la Dirección Provincial del MEC en Madrid, siendo durante ese tiempo responsable de la organización de la Campaña de Centros de Vacaciones escolares en la Provincia. Desde una óptica estrictamente política, cabe afirmar que la andadura educativa del PSOE arranca desde el despropósito, el absurdo y la desorientación. Yo tengo que ser crítico con las medidas legislativas llevadas a cabo en esta etapa por varias cuestiones. En primer lugar, cuando en 1982 el PSOE gana las elecciones generales, las expectativas de los profesionales y usuarios de la enseñanza pública alcanzan cotas insospechadas de entusiasmo. Por el contrario, la inseguridad y el miedo se incuban y estallan en el sector privado de la educación a causa de los contenidos y mensajes propagados por el partido vencedor en sus programas. Los analistas del ámbito educativo esperábamos, a partir de 1982, una primera Ley de Educación de profunda médula socialista, destinada a erradicar y suplantar a la ley Villar de 1970. Tuvimos que esperar tres años a que el PSOE, en un clima de agitación sin precedentes, protagonizado por las organizaciones empresariales, titulares de centros y Confederación Católica de Padres de Alumnos, promulgara la Ley Orgánica reguladora del Derecho a la Educación (LODE), ley de contenido sectorial y vocación revanchista, destinada a eclipsar la ordenación educativa llevada a cabo por los gobiernos de UCD. La LODE es, ante todo, una ley anti-LOECE en la medida en la que deroga el Estatuto de centros en su totalidad; una embestida ciega y visceral a la politica educativa de la UCD, y una demostración de incoherencia al dejar vigente la Ley General de Educación de 1970 en un alto grado de su contenido. Se eliminó una Ley constitucional, promulgada tras su aprobación por las Cortes Generales de la estrenada democracia y se siguieron gobernando dilatados ámbitos del sistema educativo con mecanismos legislativos de la etapa pre-constitucional y pre-democrática. 
En segundo lugar, la ratificación de la mayoría absoluta en un nuevo proceso electoral, la experiencia obtenida en el ejercicio de gobierno durante la primera legislatura socialista y la ocupación de la Administración Pública por un funcionariado de aluvión, reclutado mediante la libre designación, concursos de méritos y comisiones de servicios, asesorías, etc., dispararon al PSOE a una dinámica de reformas fácticas basadas en el voluntarismo. La técnica utilizada consistió en la producción de normas de rango inferior y la aplicación de una politica de hechos consumados con desprecio de la legalidad. La arbitrariedad sistemática y la discriminación del funcionariado preexistente integrante de los Cuerpos de la Administración se consolidan por vía legal con la promulgación de la Ley 30/84 de Medidas para la reforma de la Función Pública, que sería perfeccionada en su intencionalidad por la Ley 23/88 de 28 de julio, de modificación de la Ley anterior. Dicha Ley era una especie de lámpara de Aladino destinada a satisfacer eficazmente los más recónditos deseos del gobierno en materia de Función pública, aportando los mecanismos y habilidades necesarios para extinguir, amortizar y fundir los cuerpos históricos de la Administración española y crear, paralelamente, procedimientos blandos y flexibles de acceso a nuevos cuerpos, inventados y camuflados bajo distintos nombres e idénticas competencias que los extinguidos. Durante la redacción de la LOGSE, y en las negociaciones previas a su presentación, asistimos a diversas reuniones representantes de diversos colectivos. Recuerdo una reunión con Alfredo Pérez Rubalcaba en la que también estaban Rafael Arias Salgado y José Antonio Souto Paz, del CDS. Nos pareció necesario que se precisara el estatus de autoridad pública de los inspectores de educación (Artículo 61). Rubalcaba se mostró reticente, al considerar que ese tema estaba ya cerrado. Yo le insistí: "le hablo como inspector: es un error, pues se quedan sin autoridad. Nosotros somos sus ojos y sus oídos», a lo que me contestó: "de acuerdo, tráigamelo redactado». Y así ha quedado reflejado en la LOGSE.

Al dejar la Dirección General, Pedro Caselles se incorpora a su puesto de inspector de Educación en Valencia mediante concurso de traslados, donde permanece entre 1983 y 1986, poniendo a disposición de la Generalitat su experiencia en la Administración del Estado para llevar a cabo el traspaso de competencias educativas, especialmente en materia de inspección. Posteriormente es nombrado inspector de educación en Guadalajara y responsable del Sector de Centros Concertados, entre 
1986-1989; ese mismo año es nombrado inspector de Educación en Madrid. Entre 1990 y 1991 pasa a la esfera municipal como Consejero Técnico de Educación del Ayuntamiento madrileño con Agustín Rodríguez Sahagún. Desde esa Consejería promovió y coordinó la colección Textos básicos para la Historia Pedagógica Madrileña;48 y fue miembro del Patronato del Centro de Investigación y Documentación Pedagógicas (CEMIP). Además, fue el redactor del Estatuto de Centros Educativos del Ayuntamiento de Madrid, aprobado por unanimidad por todos los grupos políticos (19901991) para ajustarlos en sus fines, régimen jurídico y actividades a lo preceptuado en el artículo 27 de la Constitución y a las normas de carácter general que regulan los ámbitos de la Administración Educativa de la Administración Local, donde se llevó a cabo una profunda reforma del organismo en sus dimensiones materiales, personales y funcionales.

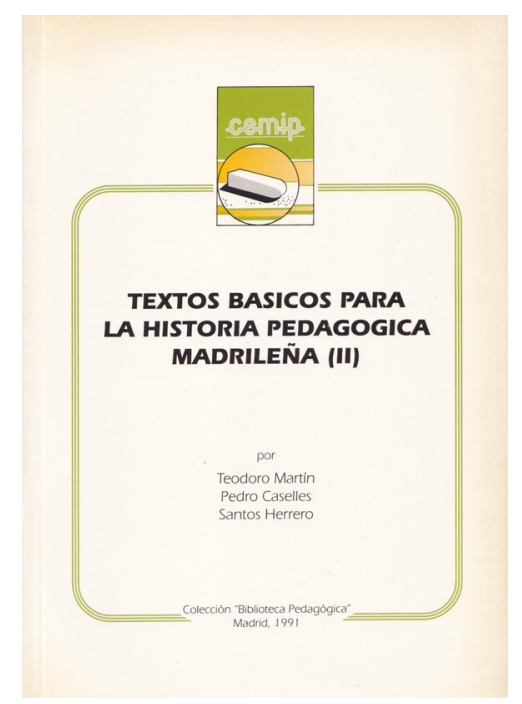

Imagen 9. Textos Básicos para la Historia Pedagógica Madrileña (Madrid: CEMIP, 1990-1991).

Posteriormente, entre 1996 y 1998 ocupó el cargo de Director del Centro de Investigación y Documentación Educativa (CIDE), un órgano directivo, con nivel orgánico de Subdirección General, que pertenecía a la estructura de la Dirección General de Educación, Formación Profesional e Innovación Educativa dependiente de la Secretaría General de Educación

48 VV. AA., Textos básicos para la Historia Pedagógica Madrileña (Madrid: CEMIP, 1990-1991). 
y Formación Profesional del Ministerio, cuya función era la innovación, experimentación y desarrollo curricular de las enseñanzas, así como la elaboración y difusión de materiales curriculares y otros documentos de apoyo para facilitar al profesorado el desempeño de sus funciones, sin perjuicio de las competencias atribuidas a la Secretaría General Técnica, y la organización y funcionamiento de la biblioteca y archivo del Departamento, en materia educativa. En aquel momento reformamos el centro y reagrupamos varios departamentos dispersos por la ciudad, y desplegamos un trabajo importante de investigación e innovación educativa, estableciendo convenios con diversos países. En 1998, el CEIP público de Tomiño, su villa natal, pasa a ser denominado «CEIP Pedro Caselles Beltrán» por iniciativa de su comunidad escolar, a la que Caselles había legado su biblioteca pedagógica. Es nombrado, además, por acuerdo municipal unánime, Hijo predilecto de Tomiño, «por su dedicación a la educación, su defensa de una mejor enseñanza y su importante labor reconocida con altas distinciones». ${ }^{49}$

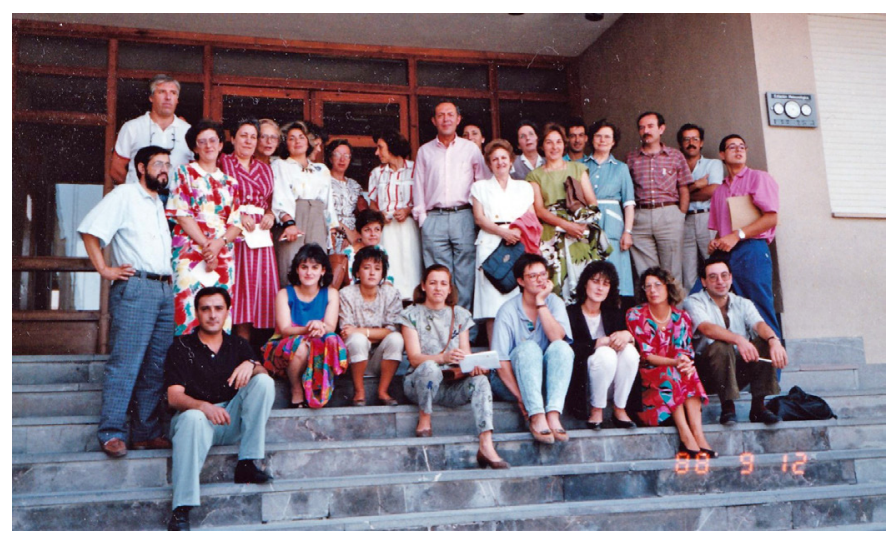

Imagen 10. Sigüenza (Guadalajara), 1988. Con un grupo de profesores y profesoras.

Como colofón a una extensa carrera dedicada al servicio público en la esfera educativa, fue nombrado Consejero de Educación y Ciencia de la Embajada de España en la Argentina, con extensión en Paraguay, Uruguay y Chile, el único puesto que yo he solicitado en mi vida profesional mediante concurso público de méritos, y que ocupó entre 1998 y su

49 «Escolares de Mosteiro agasajan a Pedro Caselles, exdirector general de Educación», Faro de Vigo, 9 de marzo de 1996. 
jubilación, en 2004. De este modo, «un veterano inspector, con tres leyes de educación a la espalda, que había visitado miles de centros públicos y privados, grandes y pequeños, urbanos y rurales...» se convierte en «el último emigrante de Tomiño en Buenos Aires».50

Desde su despacho en la Avenida de Mayo de la capital porteña, Pedro Caselles dedicó los últimos años de su vida profesional activa a alimentar su última utopía a aquella orilla del Atlántico: culminar la denominada Red de Centros Educativos Hispanos, como resultado de la firma de convenios entre instituciones pedagógicas con vocación hispanista de la Argentina, Chile, Paraguay y Uruguay, y el Ministerio español, para ampliar los conocimientos sobre historia y literatura de España, recibiendo el alumnado de los centros firmantes el título de Bachillerato con reconocimiento oficial en España, que se materializó en la inclusión de quince colegios en donde se forman en la actualidad varios centenares de jóvenes cada curso. Además de la creación de un Centro de recursos con una biblioteca especializada en temas de educación española, lugar de consulta para docentes argentinos interesados en esos temas. ${ }^{51}$

Durante esta etapa es objeto de diversos reconocimientos. En 2001, el Colegio Español «Miguel de Cervantes Saavedra» de Montevideo (Uruguay) le dedica un aula de la que da testimonio una placa conmemorativa; en 2002 es nombrado Profesor Honoris Causa por la Universidad de Ciencias Empresariales y Sociales de Buenos Aires y en 2003 es nombrado miembro Honorario del Colegio «Miguel de Cervantes» de Asunción del Paraguay.

Cuando me convertí en un profesional activo, me di cuenta de que podría hacer muchas y buenas cosas en la profesión, desde la dimensión humanista de la misma. Llegado a este punto, mi vida ha transcurrido en plenitud de paisajes, personas, vivencias y realizaciones muy variadas, siempre siguiendo el rumbo, que diría un marino; siempre siguiendo una senda, que diría un montañero... Rumbo o senda, aprendidos en la infancia y en la juventud a través de mis padres y de todas las personas que tuve la fortuna de conocer. Valores heredados y valores aprendidos, que conforman tradición,

\footnotetext{
50 «Soy el último emigrante de Tomiño en Buenos Aires», Faro de Vigo, 15 de septiembre de 1998.

51 "Pedro Caselles anuncia "una red de colegios hispanoamericanos en Sudamérica" ", Galicia en el mundo, 2-8 de junio de 2003.
} 
aprendizaje y realización. Y es así como a todos nos toca hacer una parte de la historia, con minúscula. Porque las pequeñas historias de las que somos partícipes, exigen nuestro compromiso, a veces arriesgado, que es lo verdaderamente importante.

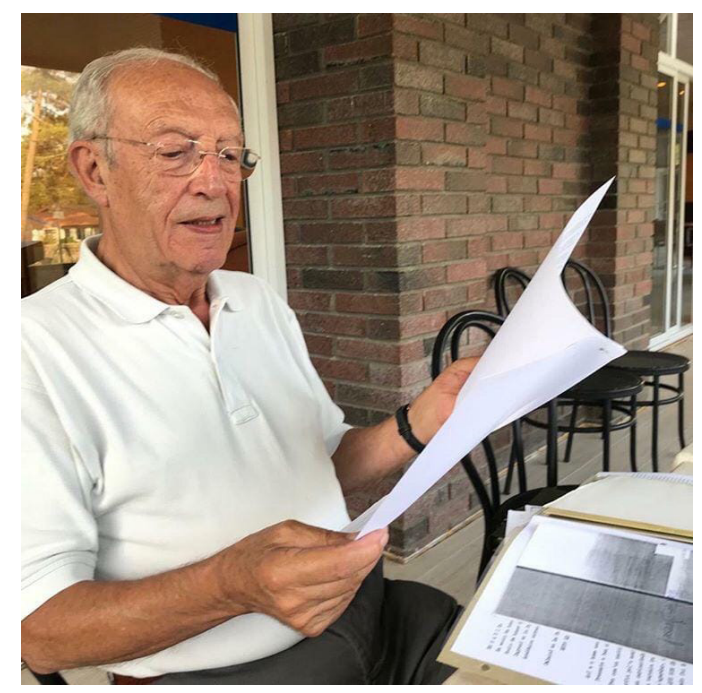

Imagen 11. A Guarda (Pontevedra), agosto de 2019.

\section{Nota sobre el autor:}

Xosé Manuel Malheiro Gutiérrez es doctor en Filosofía y Ciencias de la Educación por la Universidad de Santiago de Compostela y profesor contratado doctor en el Dpto. de Pedagoxía e Didáctica de la Facultad de Ciencias de la Educación de la Universidade da Coruña. Anteriormente lo fue en la de Vigo (2001-2002) y la de Santiago (2003-2008). Ha publicado diferentes trabajos sobre la intervención educativa de la emigración gallega a América. Es miembro de los grupos de investigación Política educativa, Historia e Sociedade (UDC) y ESCULCA (USC). Pertenece a la SEDHE y es miembro del movimiento de renovación pedagógica Nova Escola Galega. Investiga sobre los procesos migratorios y sus implicaciones en la escuela; la política educativa; el contenido de los manuales escolares; y el empleo de la fotografía y el cine como recursos para el estudio de la memoria escolar. 


\section{REFERENCIAS}

Blat Gimeno, José. «Testimonios actores de la Ley. Apuntes sobre la elaboración y aplicación de la reforma educativa de 1968-1970», Revista de Educación n. ${ }^{\circ}$ ext. «La Ley General de Educación veinte años después» (1992): 289-296.

Caselles Beltrán, Pedro. «Prólogo», en Los gitanos. Problemas socioeducativos, Alfonso Iniesta, 13-14. Madrid: Narcea, 1981.

Caselles Beltrán, Pedro. «Ley de Ordenación General del Sistema Educativo (LOGSE)», Razón y Fe. Revista Iberoamericana de Cultura 233 (1996): 261273.

Caselles Beltrán, Pedro. Las reformas educativas, un reto permanente. Buenos Aires: Universidad de Ciencias Empresariales y Sociales, 2002.

Caselles Beltrán, Pedro. Testemuños dun neno tomiñés que rematou de emigrante na Arxentina. Buenos Aires: Universidad de Belgrano, 2003.

Caselles Beltrán, Pedro. «Ser hoy y construir el mañana, o fosilizarnos. Ésa es la cuestión», en 25 años de educación en España, VV. AA., 29. Madrid: Editorial Santilla, 2003.

Costa Rico, Antón. «Conflito social e construción da educación democrática en España. Entre o Franquismo e as Reformas Socialdemócratas», en Educaçâo, Historia e Políticas. Tributo a Rogério Fernandes, coord. Fernando Cabral Pinto, 137-182. Lisboa: Ediçôes Piaget, 2015.

Costa Rico Antón y Manuel Bragado, «El libro escolar en gallego», en Historia ilustrada del libro escolar en España, Volumen II: «De la posguerra a la reforma educativa», dir. Agustín Escolano Benito, 493-518. Madrid: Fundación Sánchez Ruipérez, 1998).

Díez Hochleitner, Ricardo. "Testimonios actores de la Ley. La reforma educativa de la LGE de 1970. Datos para una crónica», Revista de Educación n. ${ }^{\circ}$ ext. «La Ley General de Educación veinte años después» (1992): 261-278.

Escolano Benito, Agustín. «Los comienzos de la modernización pedagógica en el franquismo (1951-1964)». Revista Española de Pedagogía 50, n. ${ }^{\circ} 192$ (1992): 289-310.

Escolano Benito, Agustín. «La segunda generación de manuales escolares», en Historia ilustrada del libro escolar en España, Volumen II: «De la posguerra a la reforma educativa», dir. Agustín Escolano Benito, 19-47. Madrid: Fundación Sánchez Ruipérez, 1998.

Hernández de Miguel, Carlos. Los campos de concentración de Franco. Sometimiento, torturas y muerte tras las alambradas. Barcelona: Ediciones B., 2019. López del Castillo, María Teresa. «La inspección que he vivido», en Fundamentos de supervisión educativa, coord. Eduardo Soler Fierres, 249-311. Madrid: La Muralla, 1993. 
Maíllo García, Adolfo. Historia crítica de la Inspección escolar en España. Madrid: Josmar, 1989.

Molina Armenteros, Antonio. «Entrevista. Pedro Caselles, Director General de Educación Básica. El hombre de la Reforma en EGB», Vida Escolar 220-221 (1982): 3-9.

Ossenbach Sauter, Gabriela y Alberto Martínez Boom. «Itineraries of the discourses on development and education in Spain and Latin America (circa 1950-1970)», Paedagogica Historica. International Journal of the History of Education 47 (2011): 679-700.

Puelles Benítez, Manuel de. Educación e ideología en la España contemporánea. Barcelona: Labor, 1991.

Puelles Benítez, Manuel de. Modernidad, republicanismo y democracia: una historia de la educación en España (1898-2008). Valencia: Tirant lo Blanch, 2009.

Tena Artigas, Joaquín. «Testimonios actores de la Ley Contestación al cuestionario de la Revista de Educación sobre la Ley General de Educación veinte años después», Revista de Educación n. ${ }^{\circ}$ ext. «La Ley General de Educación veinte años después» (1992): 297-306.

VV. AA. Los Programas renovados de la EGB Análisis, crítica y alternativas. Madrid, ICE/UAM: 1981.

VV. AA. Textos básicos para la Historia Pedagógica Madrileña. Madrid: CEMIP, 1990-1991.

Viñao, Antonio. «El planeamiento urbanístico-docente: un análisis de sus necesidades y problemas», Revista de Educación 264 (1980): 69-80.

Viñao, Antonio. «La Educación General Básica. Entre la realidad y el mito». Revista de Educación n. ${ }^{\circ}$ ext. "La Ley General de Educación veinte años después» (1992): 47-71.

Viñao, Antonio. «La Ley General de Educación de 1970: ¿final de una etapa? ¿comienzo de otra?», en Modernización educativa y socialización política. Contenidos curriculares y manuales escolares en España durante el tardofranquismo y la Transición democrática, ed. Manuel Ferraz Lorenzo, 125-149. Madrid: Universidad de La Laguna y Editorial Morata, 2020. 